\title{
Negative Energy Balance Blocks Neural and Behavioral Responses to Acute Stress by "Silencing" Central Glucagon-Like Peptide 1 Signaling in Rats
}

\author{
James W. Maniscalco, Huiyuan Zheng, Patrick J. Gordon, and ๑Linda Rinaman \\ Department of Neuroscience, University of Pittsburgh, Pittsburgh, Pennsylvania 15260
}

Previous reports indicate that caloric restriction attenuates anxiety and other behavioral responses to acute stress, and blunts the ability of stress to increase anterior pituitary release of adrenocorticotropic hormone. Since hindbrain glucagon-like peptide-1 (GLP-1) neurons and noradrenergic prolactin-releasing peptide (PrRP) neurons participate in behavioral and endocrine stress responses, and are sensitive to the metabolic state, we examined whether overnight food deprivation blunts stress-induced recruitment of these neurons and their downstream hypothalamic and limbic forebrain targets. A single overnight fast reduced anxiety-like behavior assessed in the elevatedplus maze and acoustic startle test, including marked attenuation of light-enhanced startle. Acute stress [i.e., 30 min restraint (RES) or 5 min elevated platform exposure] robustly activated c-Fos in GLP-1 and PrRP neurons in fed rats, but not in fasted rats. Fasting also significantly blunted the ability of acute stress to activate c-Fos expression within the anterior ventrolateral bed nucleus of the stria terminalis (vlBST). Acute RES stress suppressed dark-onset food intake in rats that were fed ad libitum, whereas central infusion of a GLP-1 receptor antagonist blocked RES-induced hypophagia, and reduced the ability of RES to activate PrRP and anterior vlBST neurons in ad libitum-fed rats. Thus, an overnight fast "silences" GLP-1 and PrRP neurons, and reduces both anxiety-like and hypophagic responses to acute stress. The partial mimicking of these fasting-induced effects in ad libitum-fed rats after GLP-1 receptor antagonism suggests a potential mechanism by which short-term negative energy balance attenuates neuroendocrine and behavioral responses to acute stress.

Key words: anxiety; fasting; food deprivation; hypophagia; nucleus of the solitary tract

Significance Statement

The results from this study reveal a potential central mechanism for the "metabolic tuning" of stress responsiveness. A single overnight fast, which markedly reduces anxiety-like behavior in rats, reduces or blocks the ability of acute stress to activate hindbrain neurons that are immunoreactive for either prolactin-releasing peptide or glucagon-like peptide 1 , and attenuates the activation of their stress-sensitive projection targets in the limbic forebrain. In nonfasted rats, central antagonism of glucagon-like peptide 1 receptors partially mimics the effect of an overnight fast by blocking the ability of acute stress to inhibit food intake, and by attenuating stress-induced activation of hindbrain and limbic forebrain neurons. We propose that caloric restriction attenuates behavioral and physiological responses to acute stress by "silencing" central glucagon-like peptide 1 signaling pathways.

\section{Introduction}

Stress responses include activation of the hypothalamic-pituitary-adrenal (HPA) axis, which is initiated by the recruitment of

Received Aug. 18, 2014; revised June 11, 2015; accepted June 15, 2015.

Author contributions: J.W.M. and L.R. designed research; J.W.M., H.Z., P.J.G., and L.R. performed research; J.W.M., P.J.G., and L.R. analyzed data; J.W.M. and L.R. wrote the paper.

This research was supported by National Institutes of Health Grant MH059911. We thank Victoria Maldovan Dzmura for expert technical assistance. We also thank Dr. Anthony Grace for use of his acoustic startle equipment, and Saiaditya Badeti for assistance in collecting the data.

The authors declare no competing financial interests.

Correspondence should be addressed to Dr. Linda Rinaman, University of Pittsburgh, Department of Neurosci-

ence, A210 Langley Hall, Pittsburgh, PA 15260. E-mail: rinaman@pitt.edu. corticotropin-releasing hormone (CRH) neurons in the paraventricular hypothalamus (PVN), and culminates in increased circulating levels of adrenocorticotropic hormone (ACTH) and glucocorticoids (Charmandari et al., 2005). In rats, the endocrine response to acute stress often is accompanied by hypophagia (suppressed food intake) and by increased anxiety-like behavior (Davis, 2002; Davis et al., 2010; Calvez et al., 2011; Maniam and Morris, 2012). Interestingly, hormonal and behavioral stress responses are profoundly modulated by metabolic state (Dallman 
et al., 1999). Caloric restriction reduces central drive to the HPA axis in rats, as evidenced by reduced PVN expression of c-Fos and CRH (Brady et al., 1990; Kiss et al., 1994; Dallman et al., 1999), and by reduced baseline and stress-evoked plasma ACTH levels (Hanson et al., 1994; Chacón et al., 2005). Downregulated CRH expression might also contribute to the reduced hypophagic responses to acute stress during periods of negative energy balance (Krahn et al., 1986, 1988; Rothwell, 1990). Food restriction or overnight deprivation reduces anxiety-like behavior in rats, as assessed in the elevated plus-maze (EPMZ) and open field tests (Genn et al., 2003; Inoue et al., 2004). Further, the amplitude of the acoustic startle response, which reflects anxiety level (Davis et al., 1997b, 2010; Walker and Davis, 1997), is reportedly reduced in rats after a period of food restriction that reduces body weight (BW) by 15\% (Martin-Iverson and Stevenson, 2005). Attenuated anxiety appears to be an adaptive response to negative energy balance, since it promotes foraging behavior and thereby increases the likelihood of body energy repletion.

Although metabolic tuning of behavioral and endocrine stress responses during caloric deficits seems adaptive, the underlying mechanisms remain unclear. We propose that reduced signaling from the caudal nucleus of the solitary tract (cNTS), specifically from prolactin-releasing peptide (PrRP)-positive $\left(\mathrm{PrRP}^{+}\right)$noradrenergic (NA) neurons of the A2 cell group $\left(\mathrm{PrRP}^{+} \mathrm{A} 2\right.$ neurons) and from glucagon-like peptide-1 (GLP-1)-positive $\left(\mathrm{GLP}-1^{+}\right)$neurons, plays a role. PrRP ${ }^{+}$A2 and GLP-1 neurons receive interoceptive feedback signals (Rinaman, 2007), optimally positioning them to monitor the metabolic state. Further, their central axonal projections contribute to stress-induced hypophagia, activation of the HPA axis, and anxiogenesis (Cecchi et al., 2002; Kinzig et al., 2003; Rinaman, 2003, 2010, 2011; Ritter et al., 2003; Rinaman and Dzmura, 2007; Schiltz and Sawchenko, 2007; Bienkowski and Rinaman, 2008; Zheng and Rinaman, 2013). Moreover, we recently reported that overnight fasting markedly reduces the ability of a visceral stressor (intraperitoneal injection of cholecystokinin) to activate A2 neurons and GLP-1 neurons, and also blunts the activation of PVN neurons (i.e., including $\mathrm{CRH}$ neurons at the apex of the HPA axis) in rats (Maniscalco and Rinaman, 2013).

The present study confirms and extends previous reports that food deprivation reduces anxiety-like behavior in rats, including marked suppression of light-enhanced acoustic startle in rats fasted overnight. We newly demonstrate in ad libitum-fed rats that acute restraint (RES) or elevated platform (EP) stress activates c-Fos expression by GLP-1 and $\mathrm{PrRP}^{+} \mathrm{A} 2$ neurons within the cNTS, and by neurons within hypothalamic and limbic forebrain target regions that receive GLP-1 and PrRP axonal input, and that an overnight fast reduces or eliminates this stressinduced neural activation. Finally, the functional relevance of fasting-induced "silencing" of cNTS neurons is supported by new experimental evidence that central GLP-1 signaling contributes to the ability of acute stress to activate c-Fos expression by limbic forebrain and hindbrain neurons, and underlies the ability of acute stress to suppress food intake in rats fed ad libitum.

\section{Materials and Methods}

Adult male Sprague Dawley rats (Harlan Laboratories) were housed singly in hanging stainless steel wire mesh cages in a temperature-controlled room $\left(20-22^{\circ} \mathrm{C}\right)$ on a $12 \mathrm{~h} \mathrm{light/dark} \mathrm{cycle} \mathrm{(lights} \mathrm{off} \mathrm{at} \mathrm{7:00} \mathrm{P.M.).} \mathrm{Rats}$ had ad libitum access to pelleted chow (catalog \#5001, Purina) and water, except as noted. All experiments were conducted in accordance with the National Institutes of Health Guide for the Care and Use of Laboratory Animals and were approved by the University of Pittsburgh Institutional
Animal Care and Use Committee. In an initial study to determine the effect of overnight fasting on body weight and blood glucose levels, experimentally naive rats $(250-270 \mathrm{~g}$ BW) were individually weighed at 4:00 P.M., and then deprived (DEP) of food (but not water) for $17 \mathrm{~h}$ overnight ( $n=5 \mathrm{DEP}$ rats) or remained ad libitum fed $(n=5)$. Rats were reweighed the following morning at 9:00 A.M., at which time blood was collected via tail nick to measure glucose levels (Contour Blood Glucose Meter and Test Strips, Bayer). The overnight change in BW for each rat was calculated. BW data and blood glucose levels were combined and averaged within the fasted and fed groups, and were compared statistically between groups using Student's $t$ test.

\section{Experiment 1}

Effect of fasting on anxiety-like behavior in the elevated plus maze. The EPMZ is a validated test of behavioral anxiety in rats that measures approach-avoidance conflict generated by the motivation and fear associated with exploring novel environments (Montgomery, 1958; Pellow et al., 1985). Experimental manipulations that increase or decrease central noradrenergic or GLP-1 receptor signaling lead to increased and decreased anxiety-like behavior in the EPMZ, respectively, as evidenced by changes in the number of entries and time spent within the "anxiogenic" open arms of the maze (Cecchi et al., 2002; Kinzig et al., 2003; Zheng and Rinaman, 2013). A significant increase in open arm time and/or entries is interpreted as reduced anxiety-like behavior, reflecting an anxiolytic treatment effect (Pellow et al., 1985). To confirm previous reports that negative energy balance reduces anxiety in rats as assessed in the EPMZ (Genn et al., 2003; Inoue et al., 2004), experimentally naive rats (225-275 $\mathrm{g} \mathrm{BW}$ ) were deprived of food (but not water) for 16-18 h overnight ( $n=$ 6 DEP rats) or were fed ad libitum $(n=6)$ before behavioral assessment. On the day of the experiment, rats were removed from their home cages between 8:30 A.M. and 10:30 A.M., and were placed into the center of the EPMZ. The EMPZ comprised two open arms $(45 \times 10 \mathrm{~cm}, \sim 550$ lux $)$ with transparent 1 -cm-high edging, and two closed arms $(45 \times 10 \times 48$ $\mathrm{cm}, \sim 12$ lux $)$ extending from a common central platform $(10 \times 10 \mathrm{~cm})$ elevated $90 \mathrm{~cm}$ above the floor. The EPMZ was located in a quiet, evenly lit behavioral testing room immediately adjacent to the animal housing room. Behavior on the EPMZ was videotaped for $5 \mathrm{~min}$, and then rats were returned to their home cages. The EPMZ was cleaned with a mild odor-neutralizing cleanser and allowed to dry between rats. Tapes were later manually scored by an investigator who was blinded to the experimental group to determine open arm time, closed arm time, center time, open arm entries, and closed arm entries, according to previously described procedures (Walf and Frye, 2007). A rat was considered to have entered a maze arm when all four paws initially occupied it. Additionally, an automated software system (ANY-maze, Stoelting Co.) was used to determine the total distance traveled on the maze by each rat during the 5 min test.

Statistics. Multivariate ANOVA was used to reveal differences between rats in the ad libitum-fed versus DEP groups on open arm time, closed arm time, center time, open arm entries, closed arm entries, total entries, and total distance traveled. Differences were considered significant at $p<0.05$.

\section{Experiment 2}

Effects of fasting on acoustic startle amplitude and light-enhanced startle. An overnight fast clearly increases the motivation of rats to seek out and procure food, which could promote increased EPMZ open arm activity independent of reduced anxiety. Thus, anxiety-like behavior in ad libitum-fed versus overnight-fasted rats also was assessed using the acoustic startle procedure (Davis et al., 1997a; Walker and Davis, 1997), which does not include an exploratory behavioral component. In the light-enhanced startle (LES) test, startle reactivity (peak amplitude) is increased in the presence of light (Walker and Davis, 1997). Baseline startle and LES each reflect anxiety-like behavior in rats, because both are increased by anxiogenic drugs and treatments, and are decreased by anxiolytic drugs and treatments (Davis et al., 1997a; Groenink et al., 2008). To test the hypothesis that overnight fasting produces anxiolytic effects, acoustic startle reflex amplitude was measured between 9:00 A.M. and 11:00 A.M. in experimentally naive ad libitum-fed $(n=8)$ and overnight 
food-deprived rats $(n=8)$ using the SR-LAB System (San Diego Instruments). To ensure similar BWs on the day of startle testing (since rats lose $\sim 9 \%$ of their BW after an overnight fast; see Results), rats selected for the fasted group were $8-10 \%$ heavier than rats in the ad libitum-fed group on the day before testing. On the day of startle testing, fasted rats weighed $259.3 \pm 2.1 \mathrm{~g}$ (range, 232-285 g), which was similar to the weights of rats in the ad libitum-fed group $(257.8 \pm 1.8 \mathrm{~g}$; range, $230-287 \mathrm{~g} ; p=0.68$, Student's $t$ test).

Rats were tested in two ventilated chambers, each containing a stabilimeter comprising a Plexiglas cylinder $(8.2 \mathrm{~cm}$ in diameter) mounted on a Plexiglas base. A tweeter mounted $24 \mathrm{~cm}$ above the cylinder provided background noise (50 dB) and delivered acoustic startle stimuli (90, 95, and $105 \mathrm{~dB}$ white noise bursts; for $50 \mathrm{~ms}$ each) in a pattern controlled by the SR-LAB software. Startle responses were transduced by a piezoelectric accelerometer mounted on a platform below the cylinder, digitized, rectified, and recorded as $1001 \mathrm{~ms}$ readings, beginning at the onset of each startle stimulus. The peak amplitude response to each startle stimulus (in millivolts) was used as the dependent measure. A standard approach for running the acoustic startle and LES protocols (Walker and Davis, 1997) was slightly modified to include interstimulus intervals that varied randomly between 20 and $40 \mathrm{~s}$, and were matched between testing chambers. Each ad libitum-fed or overnight-fasted rat was tested twice on the same day in the same chamber. Chambers and cylinders were cleaned between rats. Half of the fed and fasted rats were tested in chamber 1, and the other half in chamber 2. For each rat, after 5 min acclimation to the chamber, acoustic startle amplitudes were measured in the dark (Phase I, lights off) and subsequently in the light (Phase II; 500 lux illumination), with 60 min home-cage rest between the two tests (with no food available). The primary dependent variables for each rat were average peak startle amplitudes at each noise intensity during Phase I dark testing $(10 \times$ per intensity, presented in randomized order as per the study by Walker and Davis, 1997), average peak startle amplitudes at each noise intensity during Phase II light testing $(10 \times$ per intensity, randomized order), and the proportional change in average peak startle amplitude between Phase I and Phase II (LES) at each noise intensity level.

Statistics. Statistical analyses confirmed no chamber-based differences in acoustic startle amplitudes at any noise intensity level within either the fed or fasted groups, and so data from individual rats tested in each chamber were combined and analyzed by feeding condition. Peak startle amplitudes were analyzed by two-way repeated-measures ANOVA, with light condition (Phase I vs Phase II) and noise intensity (90, 95, and 105 $\mathrm{dB}$ ) as within-subjects repeated measures, and feeding condition (ad libitum-fed vs fasted) as the between-subjects factor. LES was analyzed by ANOVA, with feeding condition as the between-subjects factor. Differences were considered significant at $p<0.05$.

\section{Experiment 3}

Effect of fasting on neural c-Fos responses to acute stress. Experimentally naive rats (225-275 g BW) had ad libitum chow access, or were deprived of food (but not water) for 16-18 h overnight in their home cages before acute stressor treatment. On the day of the experiment, rats were removed from their home cages between 8:30 A.M. and 10:30 A.M., and were either RES in a perforated Plexiglas tube for $30 \mathrm{~min}(n=4 \mathrm{ad}$ libitum-fed rats; $n=8$ DEP rats) or were exposed to an illuminated EP (i.e., the open arm of the EPMZ, $45 \times 10 \mathrm{~cm}, \sim 550$ lux, with transparent $1 \mathrm{~cm}$-high edging, and exit blocked) for $5 \mathrm{~min}$ ( $n=6$ ad libitum-fed rats; $n=6$ DEP rats). Rats were returned to their home cages after RES or EP exposure. Additional nonhandled (NH) control rats $(n=6$ ad libitumfed rats; $n=7$ DEP rats) remained undisturbed in their home cages during the same time period.

Ninety minutes after RES or EP stressor onset, rats were deeply anesthetized with pentobarbital sodium $(39 \mathrm{mg} / 1.0 \mathrm{ml}$, i.p.; Fatal Plus Solution, Butler Schein) and perfused transcardially with a brief saline rinse followed by fixative application ( $100 \mathrm{ml}$ of $2 \%$ paraformaldehyde and $1.5 \%$ acrolein in $0.1 \mathrm{~m}$ phosphate buffer, followed by $100 \mathrm{ml}$ of $2 \%$ paraformaldehyde alone). Brains were post-fixed in situ overnight at $4^{\circ} \mathrm{C}$, then removed from the skull and cryoprotected for $24-48 \mathrm{~h}$ in $20 \%$ sucrose. Brains were blocked and sectioned coronally (35 $\mu \mathrm{m})$ using a Leica freezing-stage sliding microtome. Tissue sections were collected in six serial sets, and stored at $-20^{\circ} \mathrm{C}$ in a cryopreservant solution (Watson et al., 1986) to await immunohistochemical processing.

Immunohistochemistry. Primary and secondary antisera were diluted in $0.1 \mathrm{~m}$ phosphate buffer containing $0.3 \%$ Triton X-100 and $1 \%$ normal donkey serum. Two sets of tissue sections from each rat were incubated in a rabbit polyclonal antiserum against c-Fos (1:20,000; PC38, EMD Chemicals), followed by biotinylated donkey anti-rabbit IgG (1:500; Jackson ImmunoResearch). Sections were then treated with Elite Vectastain $\mathrm{ABC}$ reagents (Vector Laboratories) and reacted with diaminobenzidine (DAB) intensified with nickel sulfate to produce a blue-black nuclear c-Fos reaction product. To visualize c-Fos within hindbrain GLP-1 neurons, one set of c-Fos-labeled tissue sections was subsequently incubated in a rabbit polyclonal antiserum against GLP-1 (1:10,000; T-4363, Bachem), followed by biotinylated donkey anti-rabbit IgG (1: 500; Jackson ImmunoResearch), Elite Vectastain ABC reagents (Vector Laboratories), and reacted with plain $\mathrm{DAB}$ to produce a brown cytoplasmic reaction product.

The second set of c-Fos immunoperoxidase-labeled tissue sections was used to simultaneously visualize c-Fos expression by dopamine $\beta$ hydroxylase $(\mathrm{D} \beta \mathrm{H})$-positive $\left(\mathrm{D} \beta \mathrm{H}^{+}\right)$and $\operatorname{PrRP}^{+} \mathrm{A} 2$ neurons in the cNTS, and within the PrRP terminal-rich region of the anterior ventrolateral bed nucleus of the stria terminalis (vlBST). For this purpose, sections were incubated in a cocktail of mouse anti-D $\beta \mathrm{H}$ (1:5000; MAB308, Millipore) and rabbit anti-PrRP (1:1000; H-008-52, Phoenix Pharmaceuticals), followed by a cocktail of Alexa Fluor 488-conjugated donkey anti-mouse IgG (1:300; Jackson ImmunoResearch) and Cy3-conjugated donkey anti-rabbit IgG (1:300; Jackson ImmunoResearch) to produce green and red fluorescent cytoplasmic signals, respectively.

A third set of tissue sections from each rat was used to visualize c-Fos within the GLP-1 terminal-dense region of the medial parvocellular PVN (mpPVN). Tissue sets were first processed for GLP-1 immunoperoxidase labeling, as described above. Reacted sections were then incubated in one of two rabbit antisera raised against c-Fos protein: one was provided by Dr. Philip Larsen (Panum Institute, Copenhagen, Denmark) (1:5000); and the second was purchased from EMD Chemicals (1:2000; PC38). Statistical comparisons confirmed that these c-Fos antisera produced similar results. Tissue sections were then incubated in $\mathrm{Cy} 3$-conjugated donkey anti-rabbit IgG (1:300; Jackson ImmunoResearch) to produce a red fluorescent nuclear signal localizing c-Fos protein.

Imaging and quantification of c-Fos expression by GLP-1 neurons. GLP-1 neurons were visualized using a light microscope and $20 \times / 40 \times$ objectives to determine the number of GLP- $1^{+}$neurons and the proportion that were double labeled for c-Fos. GLP-1 neurons were counted bilaterally within the cNTS and adjacent reticular formation through the entire rostrocaudal extent of both GLP-1 cell groups [i.e., from the cervical spinal cord through the cNTS just rostral to the area postrema (AP); $\sim 15.46-13.15 \mathrm{~mm}$ caudal to bregma]. The criteria for counting a neuron included brown GLP-1 cytoplasmic labeling and a visible nucleus; double-labeled GLP1 neurons were those that displayed visible blueblack nuclear c-Fos immunolabeling, regardless of intensity. c-Fospositive $\left(\mathrm{c}-\mathrm{Fos}^{+}\right)$GLP-1 neurons were represented as a proportion of total GLP-1 neurons counted within the cNTS and/or reticular formation.

Imaging and quantification of $c$-Fos expression by $\operatorname{PrRP} P^{+}$and PrRPnegative A2 neurons. $\mathrm{PrRP}^{+}$and $\mathrm{PrRP}$-negative $\left(\mathrm{PrRP}^{-}\right) \mathrm{A} 2$ neurons (all of which were $\mathrm{D} \beta \mathrm{H}^{+}$) were imaged using a $20 \times$ objective on an Olympus microscope equipped for bright-field and epifluorescent illumination, and photographed using a digital camera (Hamamatsu Photonics). Neurons were counted in photographic images using Adobe Photoshop CS4 imaging software. The criteria for counting a neuron included clear cytoplasmic $\mathrm{D} \beta \mathrm{H}$ labeling and a visible nucleus. $\mathrm{PrRP}^{+} \mathrm{A} 2$ neurons also were immunopositive for cytoplasmic PrRP, whereas PrRP ${ }^{-}$A2 neurons were not. Neurons were considered to be ${\mathrm{c}-\mathrm{Fos}^{+}}^{+}$if their nucleus contained c-Fos immunoperoxidase labeling, regardless of intensity. For illustration purposes, c-Fos immunoperoxidase was photographed in the blue light channel and then inverted to facilitate the depiction of labeling in combination with immunofluorescent PrRP and D $\beta \mathrm{H}$ labeling (see Fig. 4). Single-, double-, and triple-labeled neurons were counted bilaterally through the rostrocaudal extent of the A2 cell group (i.e., from 
the cervical spinal cord through the cNTS just rostral to the AP; $\sim 15.46-13.15 \mathrm{~mm}$ caudal to bregma). In each analyzed case, c-Fos ${ }^{+}$ $\mathrm{A} 2$ neurons that were $\mathrm{PrRP}^{+}$or $\mathrm{PrRP}^{-}$were represented as a percentage of total $\mathrm{PrRP}^{+}$and $\operatorname{PrRP}{ }^{-} \mathrm{A} 2$ neurons counted, respectively.

Imaging and quantification of $c$-Fos expression in the $m p P V N$. Forebrain tissue sections labeled for GLP-1 immunoperoxidase and c-Fos immunofluorescence were viewed on the Olympus photomicroscope described above. Using a $10 \times$ objective, photographic images were captured from a single selected rostrocaudal level through the mpPVN ( $\sim 1.78 \mathrm{~mm}$ caudal to bregma). This selected level was characterized by dense GLP-1 terminal labeling that clearly defined the boundaries of the mpPVN (Maniscalco and Rinaman, 2013, their Fig. 3). c-Fos ${ }^{+}$neurons within this defined region were counted bilaterally on captured images using Adobe Photoshop CS4 imaging software. The criterion for counting a neuron as c-Fos ${ }^{+}$was the presence of visible red fluorescent nuclear immunolabeling, regardless of intensity.

Imaging and quantification of $c$-Fos expression in the PrRP terminaldense region of the anterior $v l B S T$. Forebrain tissue sections labeled for c-Fos immunoperoxidase and $\operatorname{PrRP} / \mathrm{D} \beta \mathrm{H}$ immunofluorescence were viewed on the Olympus photomicroscope described above. Using a $10 \times$ objective, photographic images were captured from a single selected rostrocaudal level of the anterior vlBST ( $\sim 0.3 \mathrm{~mm}$ caudal to bregma) that is characterized by particularly dense PrRP and $\mathrm{D} \beta \mathrm{H}$ terminal labeling (see Fig. 6). Using Adobe Photoshop CS4 imaging software, a region of interest (ROI) was mapped around the densest PrRP terminal labeling bilaterally by an investigator blinded to experimental group. c-Fos ${ }^{+}$neurons were then counted bilaterally within the defined ROI, which largely corresponded to the fusiform subnucleus of the anterior vlBST. The criterion for counting c-Fos ${ }^{+}$neurons within each ROI was the presence of blue-black nuclear immunoperoxidase labeling, regardless of intensity. The number of c-Fos ${ }^{+}$neurons per $100 \mu \mathrm{m}^{2}$ (ROI area) was quantified and averaged bilaterally in each rat. For illustration purposes, c-Fos immunoperoxidase was photographed in the blue light channel and then inverted to facilitate the depiction of labeling in combination with immunofluorescent PrRP and D $\beta \mathrm{H}$ labeling (see Fig. 6).

Statistics. Paired samples $t$ tests were used to compare the number of GLP-1 neurons located within the reticular formation versus the cNTS, and to compare c-Fos activation percentages between reticular and cNTS GLP-1 neurons following each experimental treatment. Two-way multivariate ANOVA was used to reveal the main effects and interactions between stress treatment (NH vs RES vs EP) and feeding status (ad libitum vs DEP) on c-Fos activation of GLP-1 neurons, $\operatorname{PrRP}{ }^{+}$A2 neurons, $\mathrm{PrRP}^{-}$A2 neurons, mpPVN neurons, and vlBST neurons. When $F$ values indicated significant effects, ANOVAs were followed by Fisher's least significant difference post hoc analyses. Differences were considered significant at $p<0.05$. Pearson's $R$ correlation coefficient was used to determine whether significant correlations existed between the proportion of GLP-1 neurons activated within the reticular formation and the cNTS, and between the activation of $\mathrm{PrRP}^{+} \mathrm{A} 2$ or GLP1 neurons and the activation of neurons within the mpPVN and/or anterior vlBST.

\section{Experiment 4}

Role of central GLP-1 signaling in stress-induced hypophagia and c-Fos expression. After demonstrating that acute RES stress (and EP) activates c-Fos expression by GLP-1 and PrRP ${ }^{+} \mathrm{A} 2$ neurons in ad libitum-fed rats, but not fasted rats (see Results), we next examined whether stressinduced activation of cNTS neurons contributes to behavioral responses to acute stress in nonfasted, ad libitum-fed rats. Since specific PrRP receptor antagonists are not currently available, we performed the following experiments using a specific GLP-1 receptor antagonist, exendin(9-39; Ex9), to establish a potential role of endogenous central GLP-1 signaling in RES-induced hypophagia (i.e., suppression of food intake) and activation of central c-Fos expression.

Cannulation procedures. Experimentally naive rats (285-310 g BW) were anesthetized by inhalation of isoflurane ( $1-3 \%$ in oxygen; Halocarbon Laboratories) and were placed into a stereotaxic frame in the flatskull position. Rats were fitted with long-term indwelling 21 gauge stainless steel guide cannulas (Plastics One) that were aimed at the lateral ventricle. Guide cannulae were positioned $1.4 \mathrm{~mm}$ lateral and $0.9 \mathrm{~mm}$ caudal to bregma, with the cannula tip positioned $2.7 \mathrm{~mm}$ below the surface of the skull. For intracerebroventricular infusions, a 26 gauge injector extended $1.0 \mathrm{~mm}$ beyond the tip of the guide cannula into the lateral ventricle. Cannulae were fixed to the skull with anchor screws and dental acrylic, and fitted with removable obturators that extended to the tip of the cannula. Rats were allowed to recover for $4-6 \mathrm{~d}$ after cannulation surgery, at which point all rats exceeded their presurgery BW.

RES-induced hypophagia in rats after intracerebroventricular Ex9. Beginning $4-5 \mathrm{~d}$ after surgery, ad libitum-fed rats $(n=24)$ were acclimated for $3 \mathrm{~d}$ to mock cannula injections at 6:00 P.M. This included gentle restraint by hand and obturator manipulation, which was intended to mimic the injection procedure, except for infusions. On each food intake measurement day, rats were deprived of food (but not water) for $2 \mathrm{~h}$ before dark onset. Baseline intake measures were conducted in all rats on the day before their experimental treatment day. Rats were then assigned to one of the following four experimental treatment groups: (1) intracerebroventricular saline ( $3 \mu$ l over $1.5 \mathrm{~min} ; n=6)$; (2) intracerebroventricular Ex9 (catalog \#2081, Tocris Bioscience; $100 \mu \mathrm{g}$ in $3 \mu \mathrm{l}$ of saline; $n=6)$; (3) intracerebroventricular saline plus RES; and (4) intracerebroventricular Ex9 plus RES. In Groups 3 and 4, intracerebroventricular saline or Ex9 infusions were administered 15 min before 30 min RES, which was completed just before lights out. At dark onset (7:00 P.M.), preweighed pelleted chow was placed on the home cage floor, and intake was measured to the nearest $0.1 \mathrm{~g}$ at 30 and $60 \mathrm{~min}$ (corrected for spillage beneath the cage). The amount of food consumed (in grams) was represented as the percentage of BW to correct for small between-animal BW differences.

Evaluation of cannula placement. Correct cannula placement in rats used in the hypophagia experiment was verified several days after collecting food intake data. For this purpose, water-replete rats were injected intracerebroventricularly with $2 \mu \mathrm{l}$ of sterile saline containing $5 \mathrm{ng}$ of angiotensin II (AngII; catalog \#H-1705, Bachem). Only data from rats that drank at least $5 \mathrm{ml}$ of water within $10 \mathrm{~min}$ after AngII injection are included in the study $(n=24)$.

Statistics. Food intake data at each time point $(0-30,30-60$, and a cumulative 0-60 $\mathrm{min}$ ) were analyzed by ANOVA to reveal the main effects of the experimental treatment group on chow intake, followed by post hoc $t$ tests with Bonferroni correction for multiple comparisons to reveal differences between treatment groups. Differences were considered significant at $p<0.05$.

RES-induced c-Fos expression in ad libitum-fed rats after intracerebroventricular injection of Ex9. A separate group of intracerebroventricularly cannulated rats $(n=16)$ maintained on ad libitum chow were acclimated for $3 \mathrm{~d}$ to handling and mock cannula injections as described above (see Cannulation procedures). Three of these rats were used in a small pilot study to evaluate the effect of intracerebroventricular injection alone on central c-Fos expression. For this purpose, between 9:00 A.M. and 10:00 A.M., rats were handled but received no intracerebroventricular injection $(n=1)$, injected intracerebroventricularly with saline $(n=1)$, or injected intracerebroventricularly with $\operatorname{Ex} 9(n=1$; volume and dose as in the RES-induced hypophagia experiment reported above), then were returned to their home cages. Rats were anesthetized and perfused $2 \mathrm{~h}$ after handling/injection, and their brains were processed for localization of c-Fos plus PrRP or GLP-1, as described in Experiment 3. In the handled but noninjected rat, $26 \%$ of PrRP neurons and 22\% of GLP-1 neurons were double labeled for c-Fos, which are similar to the activation values in noncannulated, nonstressed, ad libitum-fed control rats in Experiment 3 (see Results). In the rat injected intracerebroventricularly with saline solution, $31 \%$ of PrRP neurons and $58 \%$ of GLP- 1 neurons were activated, similar to the activation values in the Ex9-injected pilot rat (28\% PrRP neurons, 63\% GLP-1 neurons). Thus, intracerebroventricular injection alone activated GLP- ${ }^{+}$neurons above baseline control levels, regardless of the infusate. There were no differences in the low levels of c-Fos activation within the anterior vlBST across the three pilot study rats $\left(0.8-1.1\right.$ neurons per $\left.100 \mu \mathrm{m}^{2}\right)$, similar to the low activation levels in noncannulated, nonstressed ad libitum-fed controls in Experiment 3 (see Results). Conversely, intracerebroventricular injection robustly activated c-Fos within the mpPVN $\left(512 \mathrm{c}-F o s^{+}\right.$mpPVN cells counted in the saline rat, $576 \mathrm{c}-\mathrm{Fos}^{+} \mathrm{mpPVN}$ cells counted in the Ex 9 
rat), which exceeded mpPVN activation in noncannulated ad libitum-fed rats after acute stress in Experiment 3 (see Results). Relatively few c-Fos ${ }^{+}$ cells ( 142 cells) were counted in the mpPVN of the cannulated but noninjected pilot rat, which was similar to the counts in noncannulated, nonstressed ad libitum-fed control rats in Experiment 3 (see Results). These pilot data indicate that intracerebroventricular infusion alone, regardless of the infusate, activates GLP-1 and mpPVN neurons, but does not appear to increase PrRP or anterior vlBST neuronal activation compared with nontreated, ad libitum-fed controls.

To evaluate the effect of intracerebroventricular Ex9 pretreatment on RES-induced c-Fos, the remaining cannulated rats $(n=13)$ were removed from their home cages between 8:30 A.M. and 10:30 A.M., injected intracerebroventricularly with saline $(n=5)$ or $\operatorname{Ex} 9(n=8)$, returned to their home cages for $30 \mathrm{~min}$, subjected to RES for $30 \mathrm{~min}$, and returned again to their home cages. Two hours after intracerebroventricular injection and 90 min after RES onset, rats were deeply anesthetized and perfused transcardially with fixative, and their brains were sectioned and processed for dual immunoperoxidase localization of nuclear c-Fos (using a nickel-enhanced DAB reaction) together with cytoplasmic PrRP or GLP-1 (i.e., plain brown DAB reaction). After tissue processing, correct intracerebroventricular cannula placement was verified histologically by microscopic localization of the cannula tract targeting the lateral ventricle, and also by the presence of robust c-Fos activation of ependymal cells lining the ventricles in all intracerebroventricularly injected rats. Treatment-induced activation of $\mathrm{PrRP}^{+}$and GLP-1 ${ }^{+}$cNTS neurons, and activation within the anterior vlBST was analyzed quantitatively, as described in Experiment 3.

\section{Results}

In an initial study to evaluate the impact of overnight $(17 \mathrm{~h})$ food deprivation, DEP rats $(n=5)$ lost $\sim 9.2 \%$ of their prefasting BW (range, $-8.1 \%$ to $-10.6 \%$ ), whereas ad libitum-fed rats $(n=5$ ) gained $\sim 5 \%$ BW over the same time period (range, $4.1-6.5 \%$ ), a significant difference $(p<0.05)$. Morning blood glucose levels also were significantly reduced after an overnight fast $(63.8 \pm 3.1$ $\mathrm{mg} / \mathrm{dl}$ in DEP rats vs $94.5 \pm 2.2 \mathrm{mg} / \mathrm{dl}$ in ad libitum-fed rats; $p<0.05)$.

Experiment 1: overnight fasting reduces anxiety-like behavior on the EPMZ

Overnight DEP significantly attenuated anxiety-like behavior on the EPMZ (Fig. 1). ANOVA indicated that, compared with ad libitum-fed rats $(n=6)$, DEP rats $(n=6)$ spent significantly more time in the EPMZ open arms $\left(F_{(1,11)}=31.85 ; p<0.001\right)$ and significantly less time in the EPMZ closed arms $\left(F_{(1,11)}=\right.$ 38.09; $p<0.001)$. There was no effect of feeding status on the amount of time spent in the EPMZ center zone $\left(F_{(1,11)}=0.93\right.$; $p>0.05$; data not shown). DEP rats also made significantly more open arm entries $\left(F_{(1,11)}=405.00 ; p<0.001\right)$ but a similar number of closed arm entries $\left(F_{(1,11)}=0.15 ; p>0.05\right)$ compared with ad libitum-fed rats. There was no effect of feeding status on total distance traveled during the $5 \mathrm{~min}$ EPMZ test (DEP rats, $17.24 \pm$ $3.21 \mathrm{~m}$; ad libitum-fed rats, $16.88 \pm 1.65 \mathrm{~m} ; p>0.05)$.

\section{Experiment 2: overnight fasting reduces acoustic startle amplitude and LES}

Repeated-measures ANOVA revealed significant main effects of noise intensity $\left(F_{(2,28)}=303.7\right)$, feeding condition $\left(F_{(1,14)}=\right.$ $145.2)$, and lighting conditions $\left(F_{(1,14)}=147.0\right)$ on acoustic startle amplitude $(p<0.05$ for each). There also were significant two-way interactions between noise intensity and feeding condition $\left(F_{(2,28)}=109.2\right)$, and between lighting and feeding condition $\left(F_{(1,14)}=97.1\right)$, and a significant three-way interaction among noise intensity, lighting condition, and feeding condition $\left(F_{(2,28)}=44.1 ; p<0.05\right.$ for each $)$. Post hoc $t$ comparisons dem-
A

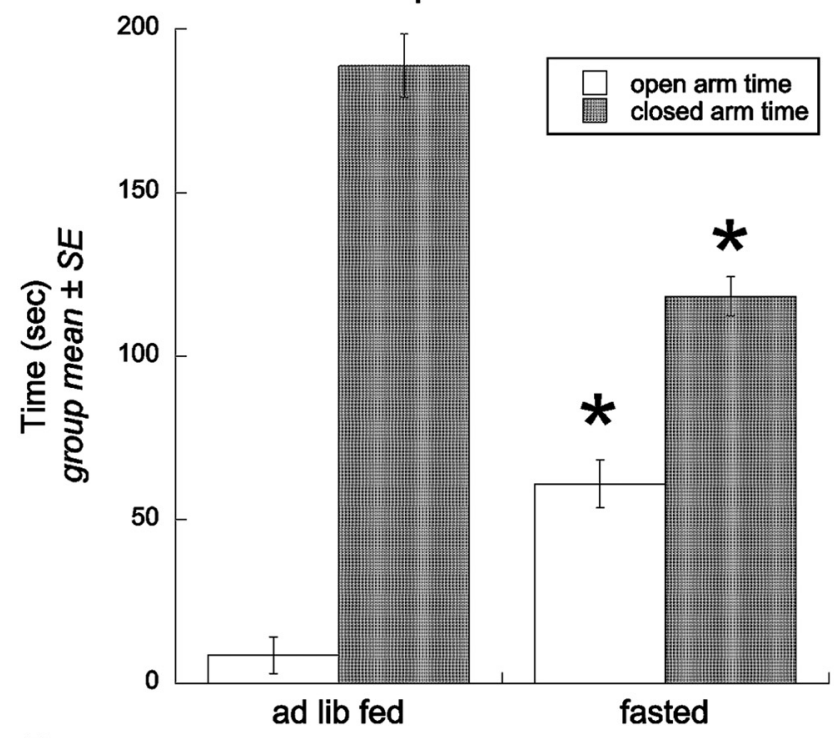

B

\section{Entries to Open vs. Closed Arms}

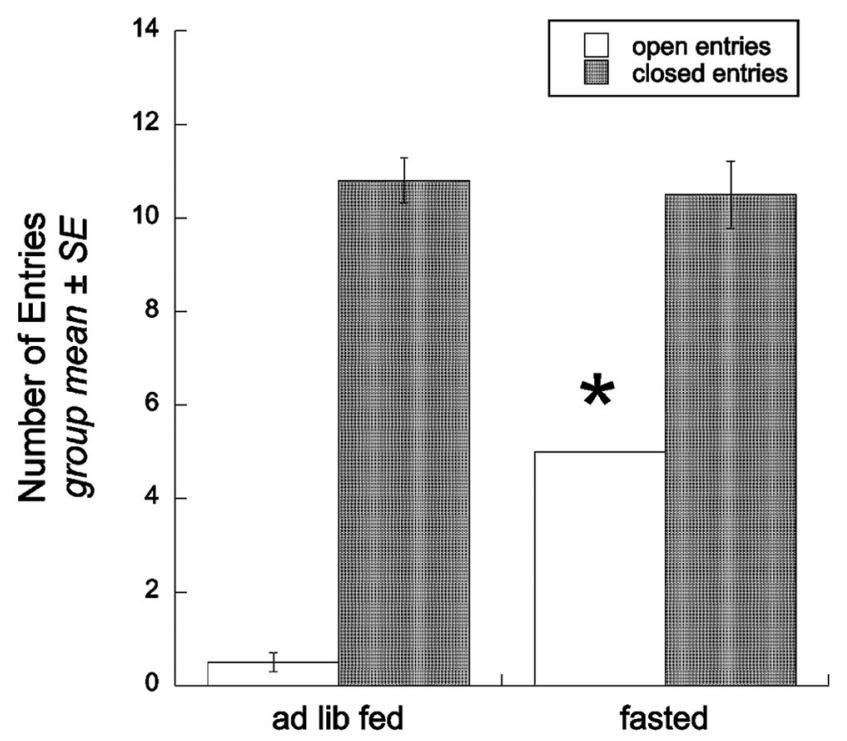

Figure 1. Overnight fasting attenuates anxiety-like behavior in the EPMZ. A, Group summary data depicting time spent in the open versus the closed arms of the EPMZ by ad libitum-fed $(n=6)$ or fasted rats $(n=6)$. $\boldsymbol{B}$, Group summary data depicting the number of open arm versus closed arm entries by ad libitum-fed or fasted rats. Asterisks indicate significant differences between ad libitum-fed and fasted groups. ${ }^{*} p<0.05$. ad lib, Ad libitum .

onstrated that acoustic startle amplitude in ad libitum-fed rats ( $n=8)$ was higher in the Phase II test (light) versus the Phase I test (dark) at each noise intensity level (Fig. 2). Acoustic startle amplitudes elicited by the 95 and $105 \mathrm{~dB}$ (but not $90 \mathrm{~dB}$ ) stimuli were increased in the Phase II (light) test in fasted rats $(n=8)$, but by much smaller amounts than in ad libitum-fed rats (Fig. $2 A$ ). A separate ANOVA based on the anxiogenic effect of light within individual subjects confirmed that the magnitude of LES at each noise intensity level was significantly lower in fasted versus fed rats (Fig. 2B).

\section{Experiment 3}

Overnight fasting reduces neural c-Fos activation after acute stress As expected, feeding status and/or stress treatment did not affect the total number of immunoreactive hindbrain GLP-1, PrRP ${ }^{+}$, 
A

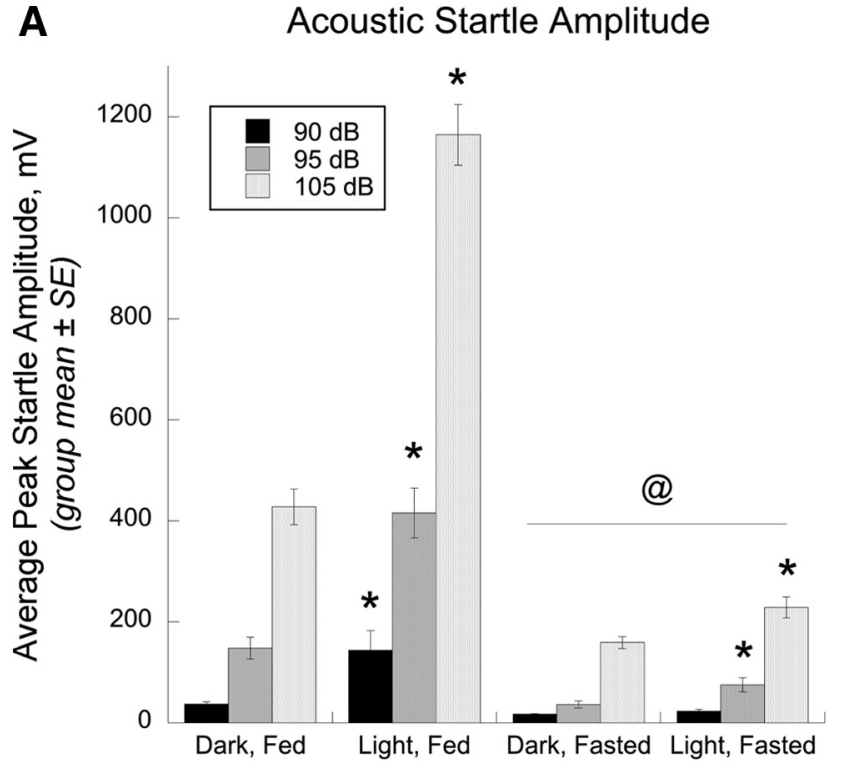

Light Level and Feeding Condition

\section{B}

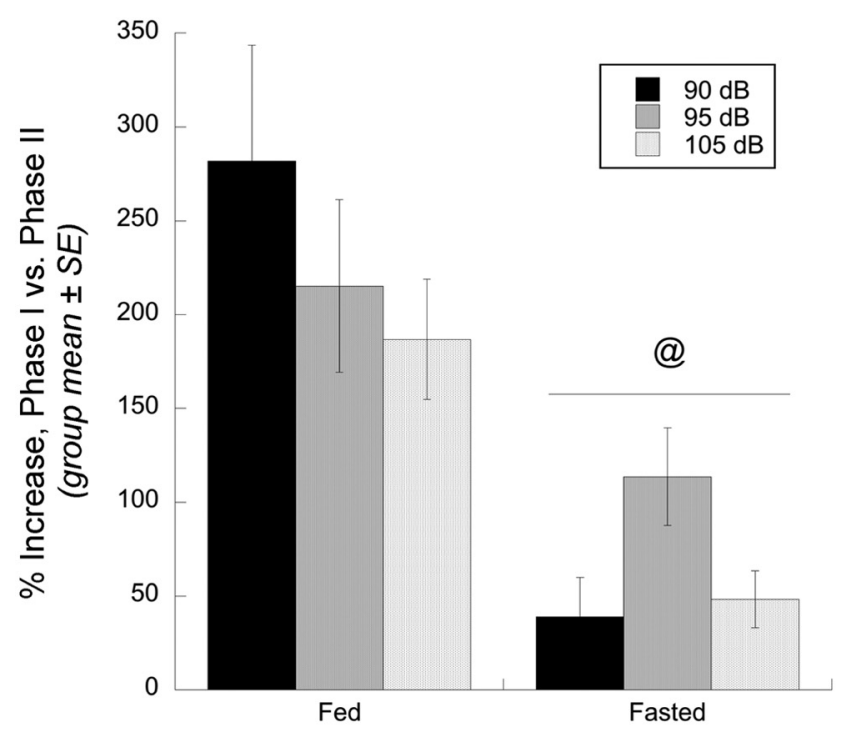

Figure 2. Overnight fasting reduces acoustic startle amplitude and attenuates lightenhanced startle. $\boldsymbol{A}$, Group summary data depicting peak startle amplitudes at each noise intensity $(90,95$, or $105 \mathrm{~dB})$ in ad libitum-fed $(n=8)$ versus overnight-fasted rats $(n=8)$ tested in Phase I "dark" versus Phase II "light" conditions. *Startle amplitude is significantly elevated in light versus dark testing conditions at all three noise intensity levels in fed rats, but only at 95 and $105 \mathrm{~dB}$ in fasted rats (within-feeding group comparisons, $p<0.05$ ); @under both lighting conditions, startle amplitudes at each noise intensity level are significantly lower in fasted versus fed rats, $p<0.05$. $B$, Group summary data depicting the magnitude of light-enhanced startle, calculated as the percentage increase in startle amplitude in Phase II (light) versus Phase I (dark) conditions at each noise intensity level. @The magnitude of light-enhanced startle is significantly lower in fasted versus fed rats at each noise intensity level, $p<0.05$.

or PrRP ${ }^{-}$A2 neurons (Table 1). However, two-way ANOVA revealed significant main effects and interactions between stressor treatment and feeding status on c-Fos expression by hindbrain GLP-1 neurons, PrRP ${ }^{+}$A2 neurons, PrRP $^{-}$A2 neurons, and within the vlBST (Table 1). There also was a significant main effect of stress treatment on c-Fos expression within the mpPVN, but no main effect of feeding status and no significant interaction effect.
Table 1. Multivariate ANOVA main effects, interactions, and $p$ values for c-Fos counts in ad libitum-fed or DEP rats following NH, RES, or EP treatment

\begin{tabular}{|c|c|c|c|}
\hline Effect source & Dependent variable & $F$ & $p$ value \\
\hline Treatment $\left(F_{(2,31)}\right)$ & $\begin{array}{l}\text { Activation of GLP-1 } \\
\text { neurons (\%) }\end{array}$ & 43.52 & $<0.001^{*}$ \\
\hline \multirow[t]{6}{*}{ NH vs RES vs EP } & $\begin{array}{l}\text { Activation of } \operatorname{PrRP}^{+} \mathrm{A} 2 \\
\text { neurons (\%) }\end{array}$ & 36.79 & $<0.001^{*}$ \\
\hline & $\begin{array}{l}\text { Activation of } \operatorname{PrRP}^{-} \mathrm{A} 2 \\
\text { neurons (\%) }\end{array}$ & 45.06 & $<0.001^{*}$ \\
\hline & $\mathrm{CFos}^{+}$Neurons in mpPVN & 21.09 & $<0.001^{*}$ \\
\hline & $\begin{array}{l}\text { cFos }^{+} \text {Neurons per } 100 \\
\mu \mathrm{m}^{2} \text { in vlBST }\end{array}$ & 71.25 & $<0.001^{*}$ \\
\hline & $\begin{array}{l}\text { Number of GLP-1 neurons } \\
\text { per section }\end{array}$ & 0.05 & $>0.05$ \\
\hline & $\begin{array}{l}\text { Number of PrRP neurons } \\
\text { per section }\end{array}$ & 2.96 & $>0.05$ \\
\hline Feeding status $\left(F_{(1,31)}\right)$ & $\begin{array}{l}\text { Activation of GLP-1 } \\
\text { neurons (\%) }\end{array}$ & 800.97 & $<0.001^{*}$ \\
\hline \multirow[t]{6}{*}{ Ad libitum vs DEP } & $\begin{array}{l}\text { Activation of } \operatorname{PrRP}^{+} \mathrm{A} 2 \\
\text { neurons (\%) }\end{array}$ & 175.87 & $<0.001^{*}$ \\
\hline & $\begin{array}{l}\text { Activation of } \operatorname{PrRP}^{-} \mathrm{A} 2 \\
\text { neurons (\%) }\end{array}$ & 29.80 & $<0.001^{*}$ \\
\hline & $\mathrm{CFos}^{+}$neurons in mpPVN & 3.51 & 0.07 \\
\hline & $\begin{array}{l}\text { CFos }^{+} \text {neurons per } 100 \\
\mu \mathrm{m}^{2} \text { in vIBST }\end{array}$ & 16.89 & $<0.001^{*}$ \\
\hline & $\begin{array}{l}\text { Number of GLP-1 neurons } \\
\text { per section }\end{array}$ & 0.02 & $>0.05$ \\
\hline & $\begin{array}{l}\text { Number of PrRP neurons } \\
\text { per section }\end{array}$ & 0.89 & $>0.05$ \\
\hline Interaction $\left(F_{(2,31)}\right)$ & $\begin{array}{l}\text { Activation of GLP-1 } \\
\text { neurons (\%) }\end{array}$ & 41.79 & $<0.001^{*}$ \\
\hline \multirow[t]{6}{*}{ Treatment $\times$ feeding status } & $\begin{array}{l}\text { Activation of } \operatorname{PrRP}^{+} \mathrm{A} 2 \\
\text { neurons (\%) }\end{array}$ & 10.88 & $<0.001^{*}$ \\
\hline & $\begin{array}{l}\text { Activation of } \operatorname{PrRP}^{-} \mathrm{A} 2 \\
\text { neurons (\%) }\end{array}$ & 6.45 & $<0.01^{*}$ \\
\hline & $\mathrm{CFos}^{+}$neurons in mpPVN & 2.50 & $>0.05$ \\
\hline & $\begin{array}{l}\text { cFos }^{+} \text {neurons per } 100 \\
\mu \mathrm{m}^{2} \text { in vlBST }\end{array}$ & 3.85 & $<0.05^{*}$ \\
\hline & $\begin{array}{l}\text { Number of GLP-1 neurons } \\
\text { per section }\end{array}$ & 0.28 & $>0.05$ \\
\hline & $\begin{array}{l}\text { Number of PrRP neurons } \\
\text { per section }\end{array}$ & 0.26 & $>0.05$ \\
\hline
\end{tabular}

*Statistically significant.

GLP-1 neuronal distribution and activation

Consistent with our recent report examining the effect of an overnight fast on visceral stress-induced neural activation (Maniscalco and Rinaman, 2013), a moderate proportion ( $232 \%)$ of GLP-1 neurons were c-Fos ${ }^{+}$in ad libitum-fed, $\mathrm{NH}$ control rats (Fig. 3E). Conversely, GLP-1 neurons did not express c-Fos in $\mathrm{NH}$ rats following DEP. Compared with baseline activation, RES and EP stress each significantly increased the proportion of GLP-1 neurons expressing c-Fos in ad libitum-fed rats, with a greater degree of activation induced by EP compared with RES (Fig. 3E). However, GLP-1 neurons were not activated in DEP rats after either RES or EP stress.

A $t$ test for paired samples demonstrated that the proportion of all GLP-1 neurons located within the cNTS (56.55 $\pm 1.37 \%)$ was significantly greater than the proportion of GLP-1 neurons located within the reticular formation $\left(43.45 \pm 1.37 \%\right.$; $t_{(36)}=$ 4.775; $p<0.001$ ). However, there were almost no significant differences between the proportion of cNTS and reticular GLP-1 neurons that expressed c-Fos after each combination of experimental treatments (Table 2). The one exception was a small but 

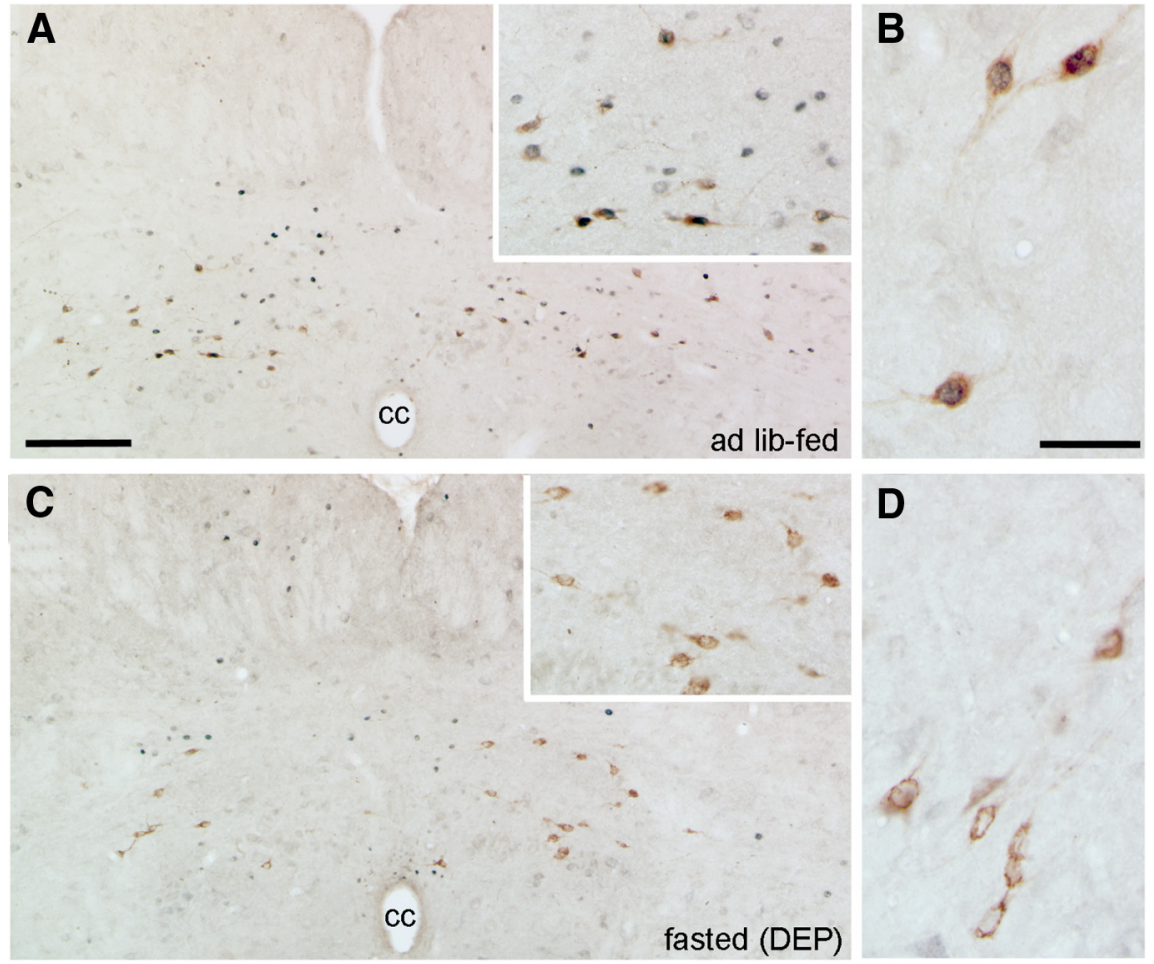

E

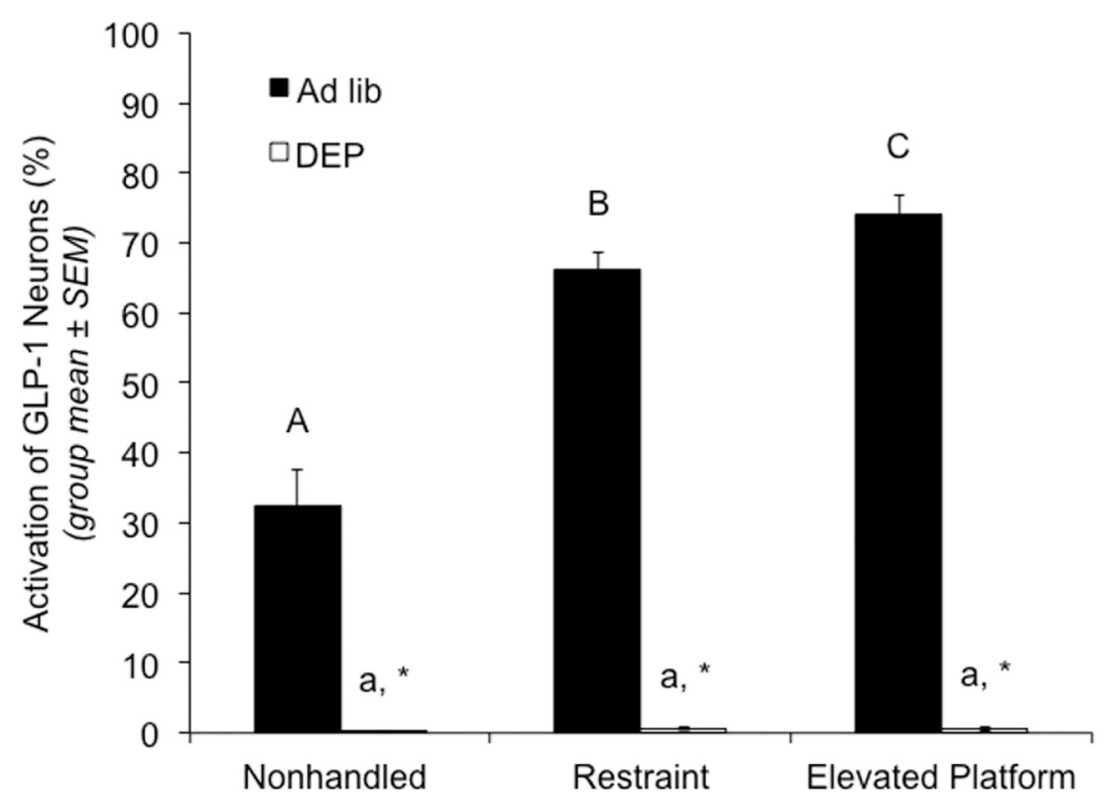

Figure 3. Fasting eliminates c-Fos activation within cNTS and medullary reticular GLP-1 neurons at baseline (nonhandled) and after acute stress. $\boldsymbol{A}-\boldsymbol{D}$, Representative color images depicting neuronal c-Fos expression (black nuclear label) within GLP-1 ${ }^{+}$ neurons (brown cytoplasmic label) in the $\operatorname{CNS}(\boldsymbol{A}, \boldsymbol{C})$ and reticular formation $(\boldsymbol{B}, \boldsymbol{D})$ in rats exposed to elevated platform stress. $\boldsymbol{A}$, Robust c-Fos activation within the cNTS $(\sim 14.36 \mathrm{~mm}$ caudal to bregma) in an ad libitum-fed rat. Inset, Higher-magnification view of several c-Fos ${ }^{+} \mathrm{GLP}-1$ neurons. $\boldsymbol{B}, \mathrm{C}-\mathrm{Fos}{ }^{+} / \mathrm{GLP}-1^{+}$neurons within the reticular formation in an ad libitum-fed rat. $\boldsymbol{C}, \mathrm{cNTS}$ $\mathrm{GLP}-1^{+}$neurons do not express c-Fos in a fasted rat after elevated platform exposure. Inset, Higher-magnification view of several GLP-1 ${ }^{+}$neurons, none of which express c-Fos. D, Reticular GLP-1 neurons do not express c-Fos in a fasted rat after elevated platform exposure. $\boldsymbol{E}$, Summary data illustrating the proportion of double-labeled neurons (i.e., both GLP-1 and c-Fos ${ }^{+}$) within the cNTS and adjacent reticular formation in ad libitum-fed rats (solid bars) or fasted rats (DEP; open bars) after no manipulation (nonhandled), after restraint stress, or after elevated platform stress. See Table 1 for two-way ANOVA results. Fasting completely eliminated c-Fos expression by GLP-1 neurons. Asterisks indicate significantly reduced ( $\left.{ }^{*} p<0.05\right)$ GLP-1 c-Fos activation in DEP rats versus ad libitum-fed rats within the same treatment group. Within the same feeding status group (i.e., ad libitum or DEP), bars with different letters (i.e., $A, B, C)$ are significantly different $(p<0.05)$, whereas bars with the same letter (a) are not. ad lib, $A d$ libitum; cc, central canal. Scale bars: (in $\boldsymbol{A}) \boldsymbol{A}, \boldsymbol{C}, 200 \mu \mathrm{m}$; (in $\boldsymbol{B}) \boldsymbol{B}, \boldsymbol{D}, 50 \mu \mathrm{m}$. statistically significant difference in the distribution of activated neurons in DEP rats after RES, in which activation was very low overall but was significantly higher among the reticular population of GLP-1 neurons. The activation of cNTS GLP-1 neurons correlated strongly with the activation of reticular GLP-1 neurons across all stress treatment conditions and both feeding groups $(r=0.972 ; p<$ 0.001 ), and also selectively within ad libitum-fed rats $(r=0.917 ; p<0.001)$. The activation of GLP-1 neurons among DEP rats was so low that the absence of a correlation within this feeding group was not surprising. While numerous studies have noted the presence of GLP-1 neurons within the caudal medullary reticular formation (Larsen et al., 1997; Rinaman, 1999a), the present study is the first to quantify and report their substantial contribution (i.e., $\sim 44 \%$ ) to the total GLP-1 neural population.

\section{A2 neuronal activation}

Ad libitum-fed rats displayed moderate c-Fos activation of $\mathrm{PrRP}^{+} \mathrm{A} 2$ neurons ( $\sim 28 \%)$ under NH control conditions, and significantly increased activation after either RES or EP (Fig. 4C), similar to GLP-1 neural activation patterns. Markedly smaller proportions of $\mathrm{PrRP}^{-} \mathrm{A} 2$ neurons expressed c-Fos under $\mathrm{NH}$ control or stress conditions (Fig. 4D). In contrast to the increased effectiveness of EP versus RES in activating GLP-1 neurons in ad libitum-fed rats (Fig. $3 E)$, RES activated significantly larger proportions of $\mathrm{PrRP}^{+}$and $\mathrm{PrRP}^{-} \mathrm{A} 2$ neurons than were activated by EP in ad libitum-fed rats (Fig. $4 C, D$ ). Similar to the effect of DEP in virtually abolishing GLP-1 neural activation under all treatment conditions (Fig. $3 E$ ), DEP eliminated c-Fos expression by $\mathrm{PrRP}^{+}$and $\mathrm{PrRP}^{-} \mathrm{A} 2$ neurons under $\mathrm{NH}$ control conditions and after EP stress (Fig. $4 C, D)$. Compared with activation in ad libitum-fed rats, DEP significantly attenuated (but did not eliminate) the ability of RES to activate both $\mathrm{PrRP}^{+}$and $\mathrm{PrRP}^{-} \mathrm{A} 2$ neurons compared with activation under $\mathrm{NH}$ control conditions or after EP.

\section{mpPVN neuronal activation}

Regardless of feeding status, c-Fos activation within the mpPVN was increased to a similar degree following RES and EP stress compared with NH controls (Table 1, Fig. 5). A main effect of feeding status on c-Fos counts approached, but did not reach, statistical significance ( $p=0.07$; Table 1$)$, and there was no significant interaction between feeding status and stress treatment on mpPVN c-Fos counts. Although the ANOVA results 
Table 2. Paired-samples $t$ tests comparing mean differences between the proportion of NTS GLP-1 neurons and reticular GLP-1 neurons activated to express c-Fos following each experimental treatment combination

\begin{tabular}{|c|c|c|c|c|c|c|c|c|}
\hline \multirow[b]{2}{*}{ Feeding status } & \multirow[b]{2}{*}{ Treatment } & \multicolumn{2}{|l|}{ NTS } & \multicolumn{2}{|c|}{ Reticular } & \multirow[b]{2}{*}{$t(\mathrm{df})$} & \multirow[b]{2}{*}{$p$ value } & \multirow[b]{2}{*}{$n$} \\
\hline & & Mean & SEM & Mean & SEM & & & \\
\hline \multirow[t]{3}{*}{ Ad libitum } & NH & 33.80 & 6.69 & 30.55 & 4.01 & $0.787(5)$ & $>0.05$ & 6 \\
\hline & RES & 69.91 & 1.95 & 61.08 & 4.39 & $2.503(3)$ & $>0.05$ & 4 \\
\hline & EP & 73.90 & 2.97 & 74.82 & 3.37 & $0.289(5)$ & $>0.05$ & 6 \\
\hline \multirow[t]{3}{*}{ DEP } & NH & 0.26 & 0.26 & 0.00 & 0.00 & $1.000(6)$ & $>0.05$ & I \\
\hline & RES & 0.00 & 0.00 & 1.52 & 0.48 & $3.133(7)$ & $<0.05^{*}$ & 8 \\
\hline & EP & 0.14 & 0.14 & 1.02 & 0.80 & $1.032(5)$ & $>0.05$ & 6 \\
\hline
\end{tabular}

*Statistically significant.

formally preclude post hoct comparisons between ad libitum-fed and DEP rats in each stress treatment group, the data shown in Figure 5 are consistent with the hypothesis that DEP reduced c-Fos activation in the mpPVN under NH control conditions and after EP stress, but not after RES.

\section{Anterior vlBST neuronal activation}

Low baseline levels of c-Fos expression were present within the vlBST in NH control rats, regardless of feeding status (Fig. 6C). RES and EP stress each significantly increased vlBST c-Fos expression, with RES stress evoking a larger increase than EP stress (Fig. $6 C$ ). The ability of RES or EP to activate c-Fos in the vlBST was modestly but significantly attenuated in DEP rats, in which RES-induced c-Fos activation remained significantly higher than activation after EP stress (Table 1, Fig. 6C).

\section{Experiment 4: role of central GLP-1 signaling in stress- induced hypophagia and c-Fos activation in ad libitum-fed rats}

ANOVA indicated significant main effects of experimental treatment group on food intake at the $0-30 \mathrm{~min}$ time point $\left(F_{(3,23)}=\right.$ $14.3 ; p<0.001)$ and also cumulatively from 0 to $60 \mathrm{~min}\left(F_{(3,23)}=\right.$ 216.254; $p=0.012$ ), although no significant treatment effect was observed in the 30-60 min time period. As depicted in Figure 7, post hoc $t$ comparisons during the first $30 \mathrm{~min}(0-30 \mathrm{~min})$ and cumulatively $(0-60 \mathrm{~min})$ confirmed that intracerebroventricular injection of saline followed by RES significantly reduced food intake compared with intake under baseline conditions, and also compared with intake by rats in each experimental treatment group (Fig. $7 ; n=24$ rats for baseline data, and $n=6$ rats per experimental group). Food intake was statistically similar in rats under baseline, intracerebroventricularly injected saline, and intracerebroventricularly injected Ex9 plus RES conditions (Fig. 7). Thus, intracerebroventricular injection of Ex9 by itself did not affect food intake in the absence of RES stress, but prevented the hypophagic response to RES (Fig. 7).

In addition to blocking RES-induced hypophagia, intracerebroventricular injection of Ex9 significantly attenuated the ability of RES to activate PrRP neurons within the cNTS, and to activate neurons within the PrRP terminal-rich anterior vlBST in ad libitum-fed rats (Fig. $8 ; p<0.05$ for each comparison, saline vs Ex9). Conversely, $\sim 75-80 \%$ of GLP-1 neurons were activated after RES, regardless of intracerebroventricular pretreatment (Fig. 8). As stated in Materials and Methods, our pilot study indicated that intracerebroventricular injection alone activated $\sim 60 \%$ of GLP- 1 neurons (similar to the effect of RES in noncannulated, ad libitum-fed rats), and also activated robust c-Fos expression within the mpPVN that exceeded activation after RES in noncannulated ad libitum-fed control rats (Experiment 3). This robust $\mathrm{mpPVN}$ activation prevented the detection of an intrace- rebroventricular pretreatment effect on RES-induced mpPVN activation, and so the mpPVN data were not quantified or analyzed statistically.

\section{Discussion}

Previous reports indicate that caloric deficits attenuate anxietylike behavior and stress-induced hypophagia in rats (Lennie et al., 1995; Youngblood et al., 1997; Heiderstadt et al., 2000; MartinIverson and Stevenson, 2005; Levay et al., 2007). The present study established that overnight fasting reduces anxiety-like behavior on the EPMZ. Fed rats spent most of the 5 min EPMZ test moving between the two closed arms, with very little open arm exploration. Conversely, fasted rats allocated significantly more time to exploring the illuminated, "anxiogenic" open arms, reflecting an anxiolytic effect of caloric deficit. Interestingly, there were no differences between fed and fasted rats in total distance traveled on the maze, arguing against a general fasting-induced increase in locomotion. However, since increased motivation to feed could account for increased open arm exploration in the EPMZ test, independent of decreased anxiety, behavior in another group of fed and fasted rats was assayed using the acoustic startle test, which does not include an exploratory component. In the LES test, baseline startle reactivity (peak amplitude) is increased in the presence of light, which is anxiogenic in rats (Walker and Davis, 1997). Acoustic startle amplitudes are suppressed in rats after a longer period of food restriction that reduces BW by 15\% (Martin-Iverson and Stevenson, 2005), and the present results newly indicate that baseline startle amplitudes and the magnitude of LES are significantly reduced in rats after a single overnight fast. Since baseline startle amplitude and LES are increased by anxiogenic drugs and treatments, and are decreased by anxiolytic drugs and treatments (Davis et al., 1997a; Groenink et al., 2008), the present results support the view that overnight fasting is anxiolytic.

As discussed below, our new findings reveal a potential mechanism for fasting-induced shifts in stress responsiveness and anxiety-like behavior. Specifically, we report that overnight food deprivation nearly abolishes the ability of stress to activate GLP-1 and $\mathrm{PrRP}^{+} \mathrm{A} 2$ neurons within the cNTS. We further demonstrate that central GLP-1 receptor signaling is necessary for the ability of acute RES stress to suppress food intake in nondeprived rats, and also to fully activate PrRP neurons and neurons within the anterior vlBST. Thus, fasting-induced "silencing" of GLP-1 neurons (and perhaps $\mathrm{PrRP}^{+} \mathrm{A} 2$ neurons) is a potential mechanism through which negative energy balance decreases behavioral stress responsiveness.

\section{Fasting suppresses GLP-1 neuronal activation}

The majority of GLP-1 neurons within the cNTS and medullary reticular formation were activated in fed rats after RES or EP 

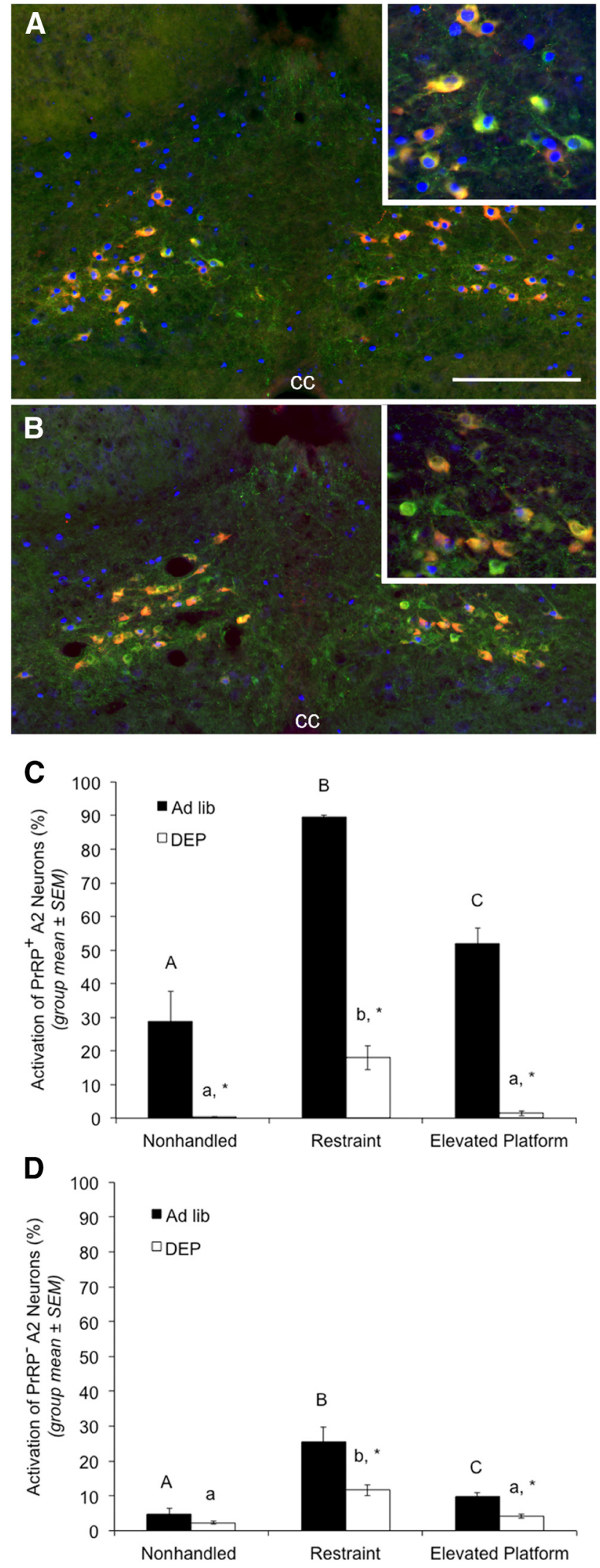

Figure 4. Overnight fasting (DEP) reduces the activation of noradrenergic PrRP ${ }^{+}$and PrRP $^{-}$A2 neurons at baseline and after acute stress. $\boldsymbol{A}, \boldsymbol{B}$, Representative color images of sections through the cNTS ( $\sim 14.36 \mathrm{~mm}$ caudal to bregma) from two rats exposed to restraint stress. Sections are triple labeled for neuronal c-Fos expression (blue nuclear label), PrRP (red), and $\mathrm{D} \beta \mathrm{H}$ (green). All PrRP ${ }^{+}$neurons are also $\mathrm{D} \beta \mathrm{H}^{+}$and thus appear yellow/orange.

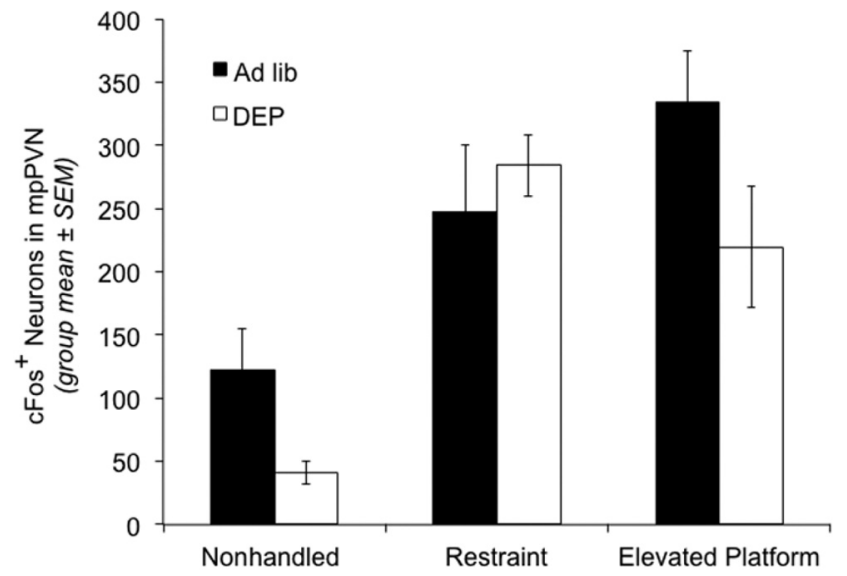

Figure 5. Summary data illustrating the number of $\mathrm{c}-\mathrm{Fos}^{+}$neurons within the GLP-1 terminal-rich region of the mpPVN in ad libitum-fed rats (solid bars) or fasted rats (DEP; open bars) after no manipulation (nonhandled; $n=6$ ad libitum, $n=7 \mathrm{DEP}$ ), restraint stress $(n=4$ ad libitum, $n=8 \mathrm{DEP}$ ), or elevated platform stress ( $n=6$ ad libitum, $n=6 \mathrm{DEP}$ ). Compared with nonhandled control rats, either restraint or elevated platform exposure increased c-Fos expression within the mpPVN, regardless of feeding status. Despite the apparent trend toward reduced mpPVN c-Fos activation in fasted rats under nonhandled control conditions or after elevated platform exposure, there was no significant main effect of feeding status, and no interaction between feeding status and stress treatment on mpPVN c-Fos activation (see Table 1 for two-way ANOVA results). ad lib, Ad libitum.

stress. Since GLP-1 neurons in rats are glutamatergic (Zheng et al., 2015) and their axon terminals synapse directly onto mpPVN CRH neurons (Sarkar et al., 2003), stress-induced activation of these neurons likely contributes to the activation of the HPA axis. Indeed, GLP-1 receptor signaling facilitates glutamate release and increases PVN neuronal spike frequency (Acuna-Goycolea and van den Pol, 2004). In contrast to results in fed rats, GLP-1 c-Fos activation was abolished in fasted rats across all treatment conditions. This extends previous findings that fasting eliminates GLP-1 activation after systemically administered cholecystokinin, which recruits vagal (visceral) sensory inputs to the cNTS (Maniscalco and Rinaman, 2013). There was no difference between cNTS and reticular GLP-1 populations in their response to acute RES or EP stress (Table 2), suggesting that both populations receive similar inputs conveying cognitive stress signals from the forebrain to the hindbrain (Dayas and Day, 2001; Dayas et al., 2004).

Green cells are $D \beta \mathrm{H}^{+} / \mathrm{PrRP}^{-} \mathrm{A2}$ neurons. $\boldsymbol{A}$, Restraint robustly activates cNTS c-Fos expression in an ad libitum-fed rat, including activation of most $\operatorname{PrRP}^{+} / \mathrm{D} \beta \mathrm{H}^{+}$neurons and a smaller proportion of $\mathrm{PrRP}^{-} / \mathrm{D} \beta \mathrm{H}^{+}$neurons. Inset, Higher-magnification view of several c-Fos ${ }^{+} /$ $\mathrm{PrRP}^{+} / \mathrm{D} \beta \mathrm{H}^{+}$neurons. B, Restraint activates relatively few $\operatorname{PrRP}^{+} / \mathrm{D} \beta \mathrm{H}^{+}$or $\mathrm{PrRP}^{-} /$ $D \beta \mathrm{H}^{+}$neurons in a fasted rat. Inset, Higher-magnification view of several $\operatorname{PrRP}^{+} / \mathrm{D} \beta \mathrm{H}^{+}$and $\mathrm{PrRP}^{-} / D \beta \mathrm{H}^{+}$neurons, some of which express C-Fos. C, D, Summary data reporting the proportion of PrRP ${ }^{+} / D \beta H^{+}$neurons expressing C - Fos $(C)$, or PrRP ${ }^{-} / D \beta H^{+}$neurons expressing c-Fos (D) in ad libitum-fed rats (solid bars) or fasted rats (DEP; open bars) after no manipulation (nonhandled; $n=6$ ad libitum, $n=7 \mathrm{DEP}$ ), restraint stress ( $n=4$ ad libitum, $n=8 \mathrm{DEP}$ ), or elevated platform stress ( $n=6$ ad libitum, $n=6$ DEP). C, DEP eliminated $c$-Fos expression by $\mathrm{PrRP}^{+} / \mathrm{D} \beta \mathrm{H}^{+}$neurons in nonhandled control rats or in rats after elevated platform stress and significantly reduced c-Fos expression by $\mathrm{PrRP}^{+} / \mathrm{D} \beta \mathrm{H}^{+}$neurons in rats exposed to restraint. $D$, Relatively few PrRP ${ }^{-} / D \beta H^{+}$neurons expressed c-Fos in nonhandled control rats, regardless of feeding status. Fasting attenuated stress-induced c-Fos expression in $\operatorname{PrRP}^{-} / D \beta \mathrm{H}^{+}$ neurons. See Table 1 for two-way ANOVA results. In $\boldsymbol{C}$ and $\boldsymbol{D}$, asterisks indicate significantly reduced $\left({ }^{*} p<0.05\right)$ neural c-Fos expression in DEP versus ad libitum-fed rats in the same stress group. Within the same feeding status group (i.e., ad libitum or DEP), bars with different letters (i.e., $A, B, C$ or a , b , c) are significantly different $(p<0.05)$. ad lib, Ad libitum; $c c$, central canal. Scale bar: (in $A) A, B, 200 \mu \mathrm{m}$. 

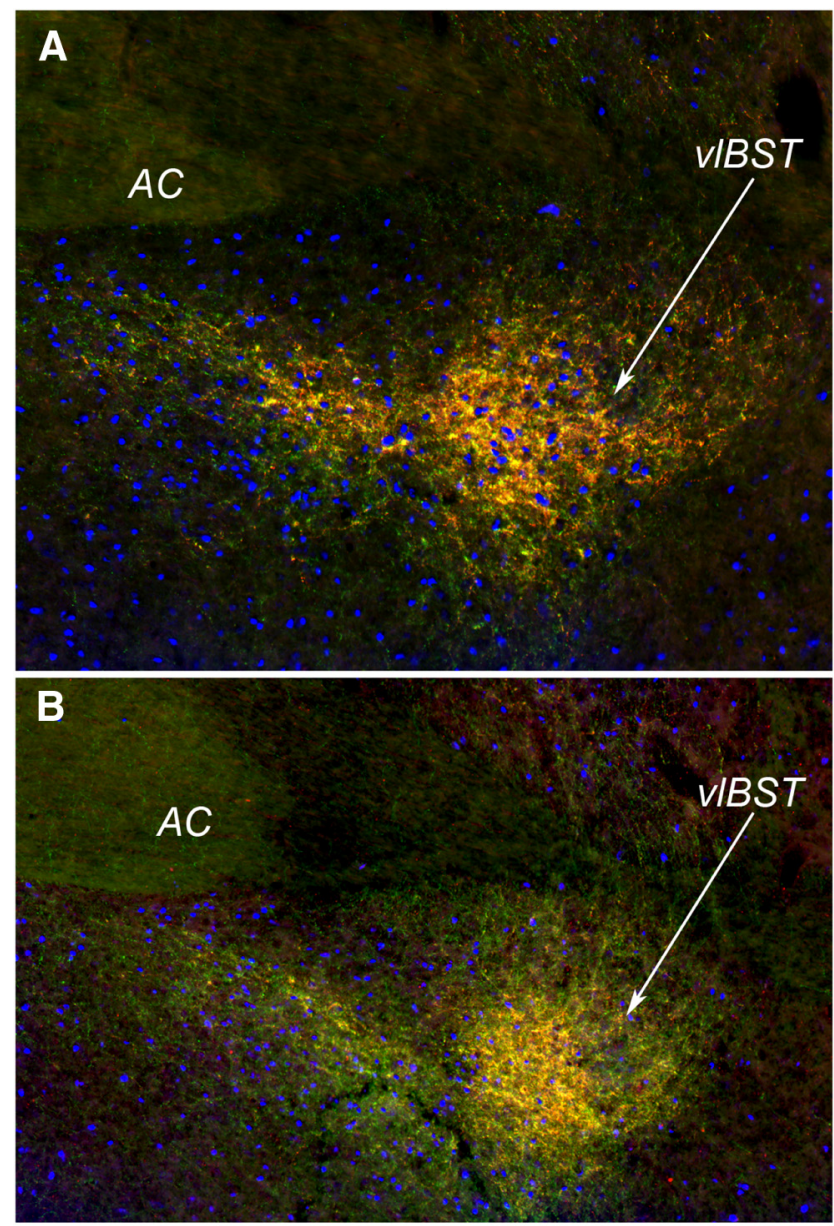

C

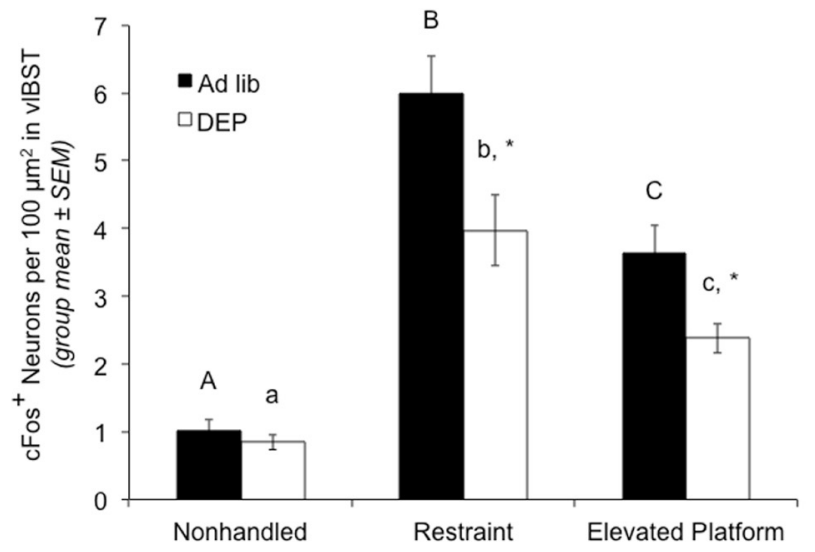

Figure 6. Fasting reduces c-Fos activation within the anterior vIBST after acute stress. $\boldsymbol{A}, \boldsymbol{B}$, Representative color images depicting neuronal c-Fos expression (blue nuclear label) within the coextensive PrRP (red) and D $\beta$ H (green) terminal-rich region of the vIBST ( $\sim 0.26 \mathrm{~mm}$ caudal to bregma). $A$, In an ad libitum-fed rat, many neurons within and surrounding the vIBST express c-Fos after restraint. $\boldsymbol{B}$, Fewer vIBST neurons express $\mathrm{c}-$ Fos in a fasted rat after restraint. $\boldsymbol{C}$, Summary data reporting the number of c-Fos ${ }^{+}$neurons per $100 \mu \mathrm{m}^{2}$ area of the PrRP/D $\beta H$ terminal-rich vIBST in ad libitum-fed rats (solid bars) or fasted rats (DEP; open bars) after no manipulation (nonhandled; $n=6$ ad libitum, $n=7$ DEP), restraint stress ( $n=4$ ad libitum, $n=8 \mathrm{DEP})$, or elevated platform stress ( $n=6$ ad libitum, $n=6 \mathrm{DEP}$ ). See Table 1 for two-way ANOVA results. Fasting did not affect baseline $c-$ Fos, but significantly attenuated stress-induced $c-$ Fos expression in the vIBST. Asterisks indicate significantly reduced $\left({ }^{*} p<0.05\right)$ vIBST neural $c$-Fos expression in DEP rats versus ad libitum-fed rats in the same treatment group. Within the same feeding status group (i.e., ad libitum or DEP), bars with different letters (i.e., A, B, C or a, b, c) are significantly different $(p<0.05)$. AC, Anterior commissure; ad lib, Ad libitum. Scale bar: (in $A) A, B, 200 \mu \mathrm{m}$.

\section{Dark Onset Food Intake}

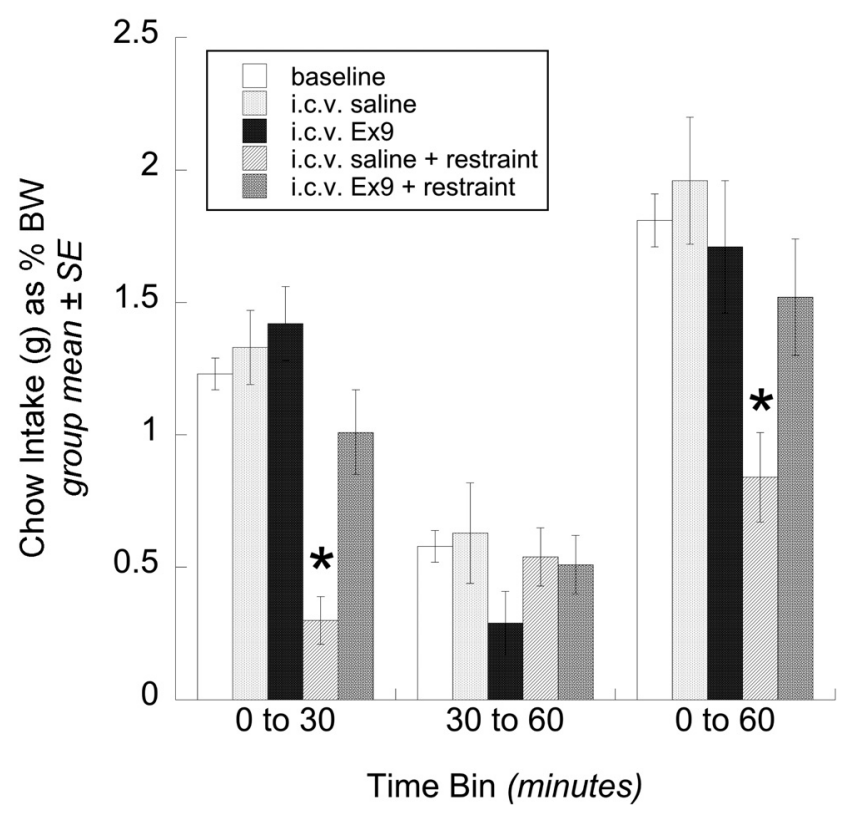

Figure 7. The ability of restraint stress to suppress dark-onset food intake in ad libitum-fed rats is blocked by lateral intracerebroventricular administration of a specific GLP-1 receptor antagonist (Ex9). Chow intake (expressed as a percentage of body weight) is illustrated from 0 to $30 \mathrm{~min}$, from 30 to $60 \mathrm{~min}$, and cumulatively $(0-60 \mathrm{~min})$ at baseline $(n=24)$, and after each experimental treatment ( $n=6 / \mathrm{group}$ ). Control intracerebroventricular infusion of saline vehicle or Ex9 alone did not alter chow intake. After intracerebroventricular infusion of saline, restraint stress significantly reduced food intake during the first $30 \mathrm{~min}$. This hypophagic effect was not compensated for during the second 30 min period, such that the cumulative $60 \mathrm{~min}$ intake remained suppressed. Pretreatment with intracerebroventricular injection of Ex 9 significantly attenuated restraint stress-induced hypophagia during the first $30 \mathrm{~min}$ and at the $\mathrm{Cu}-$ mulative 60 min time point. ${ }^{*}$ Significantly less intake $(p<0.05)$ compared with baseline and compared with intake by rats in all other treatment groups within the same time bin.

The consequences of GLP-1 "silencing" in fasted rats likely include anxiolysis, blunted HPA axis activation (Kinzig et al., 2003), and attenuation of other stress responses in which central GLP-1 receptor signaling has been implicated (O'Shea et al., 1996; Gülpinar et al., 2000; Yamamoto et al., 2002). Paradoxically, however, food deprivation increases plasma corticosterone (CORT) at baseline and after acute restraint stress, despite concurrently reduced plasma ACTH (Akana et al., 1994; Chacón et al., 2005). This may facilitate glucose mobilization for energydependent functions during periods of caloric deficit (Dallman et al., 1999).

Central GLP-1 signaling suppresses food intake (Turton et al., 1996; Rinaman, 1999b), and previous reports using Ex9 indicate that endogenous GLP-1 receptor signaling is necessary for the suppression of food intake after visceral stress (Rinaman, 1999b; Grill et al., 2004). In the present study, intracerebroventricular saline infusion followed by RES stress reduced dark-onset food intake by $70 \%$ during the first $30 \mathrm{~min}$, and by $60 \%$ overall during the first hour, which is consistent with previous reports that RES suppresses food intake (Krahn et al., 1986; Rybkin et al., 1997; Calvez et al., 2011). Importantly, the hypophagic response to RES was abolished by intracerebroventricular pretreatment with Ex9, which (in different rats) also significantly attenuated the ability of RES to activate PrRP neurons in the cNTS and neurons within the anterior vlBST. These results support the view that endogenous GLP-1 receptor signaling is necessary for acute stress-induced hypophagia, which may depend on the activation of $\operatorname{PrRP}^{+} \mathrm{A} 2$ 

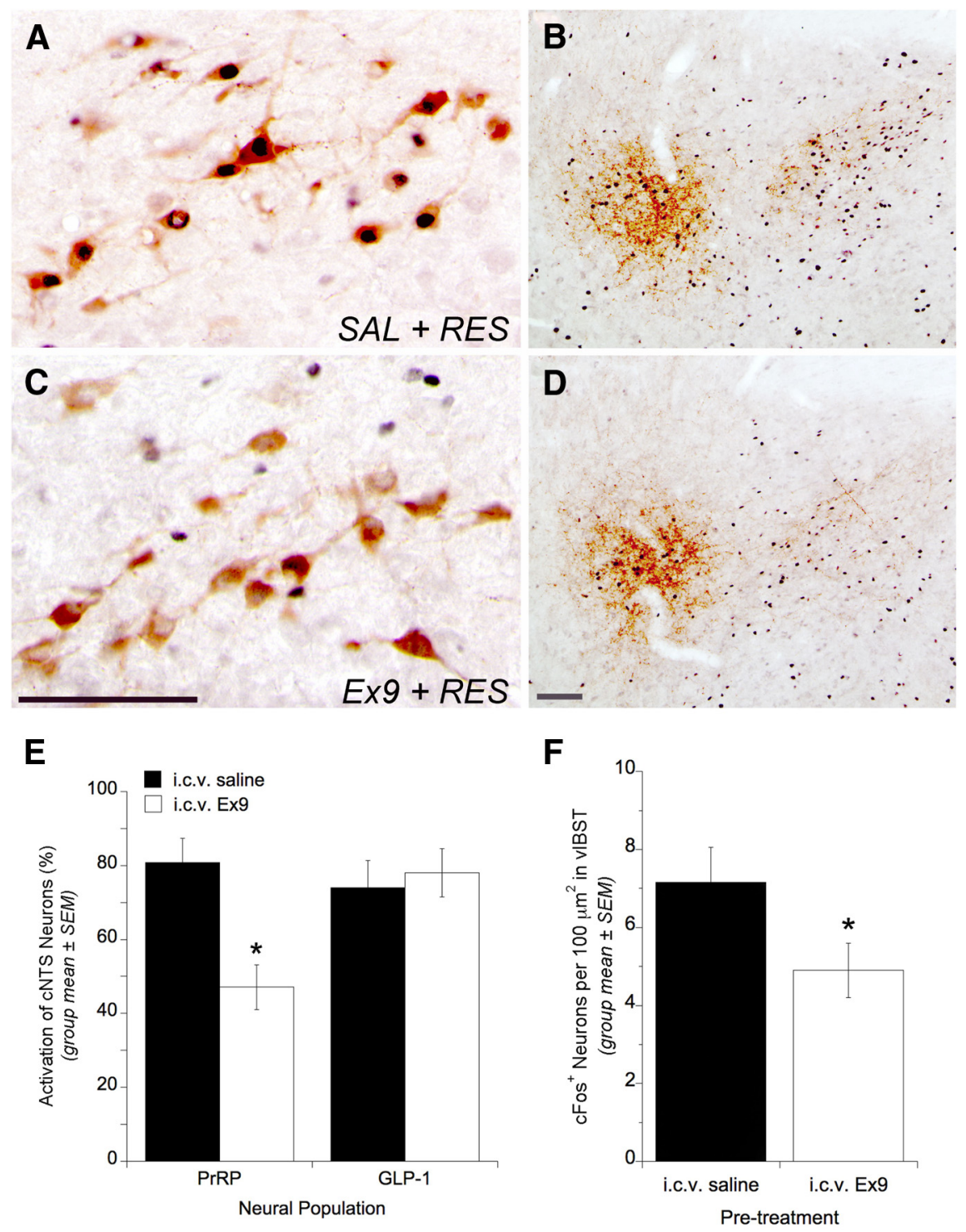

Figure 8. Lateral intracerebroventricular infusion of a GLP-1 receptor antagonist (Ex9) significantly reduces the ability of RES stress to activate PrRP ${ }^{+}$cNTS neurons and neurons within the anterior vIBST in ad libitum-fed rats. $A$, The majority of PrRP ${ }^{+}$ neurons (brown) express c-Fos (black nuclei) after RES in rats pretreated with intracerebroventricular injection of saline (SAL). $\boldsymbol{B}$, RES-induced c-Fos within the PrRP-rich anterior vlBST in a rat treated with intracerebroventricularly injected saline after RES. C, RES-induced activation of PrRP neurons is reduced in rats pretreated with intracerebroventricular injection of Ex9. D, RES-induced activation of neurons within the PrRP-rich anterior vIBST is reduced in rats pretreated with intracerebroventricular injection of Ex9. $E$, Quantification of RES-induced activation of PrRP and GLP-1 neurons in rats pretreated with intracerebroventricular injection of either saline $(n=5)$ or Ex9 $(n=8) ;{ }^{*} p<0.05$, intracerebroventricular saline vs Ex9. $\boldsymbol{F}$, Quantification of RES-induced activation within the anterior vIBST in rats pretreated intracerebroventricularly with either saline $(n=5)$ or $\operatorname{Ex} 9(n=8)$; ${ }^{*} p<0.05$, intracerebroventricularly injected saline vs Ex9. Scale bars: (in $C, D) A-D, 200 \mu \mathrm{m}$.

neurons and their downstream targets. This new finding complements a previous report implicating central GLP1 signaling in hormonal and anxiogenic responses to acute stress in rats (Kinzig et al., 2003). Thus, fasting-induced "silencing" of hindbrain GLP-1 neurons, at least as measured by c-Fos expression, is a viable mechanism through which fasting can retune physiological and behavioral responses to stress.

\section{Fasting suppresses activation of $\mathrm{PrRP}^{+} \mathrm{NA}$ neurons}

Acute stress significantly increased c-Fos activation of $\mathrm{PrRP}^{+} \mathrm{A} 2$ neurons in ad libitum-fed rats, with a higher proportion of activated neurons after RES ( $\sim 90 \%)$ compared with EP exposure $(\sim$ $52 \%)$. These results extend previous reports that $\mathrm{PrRP}^{+} \mathrm{A} 2 \mathrm{neu}-$ rons are stress sensitive (Maruyama et al., 2001; Morales and Sawchenko, 2003; Zhu and Onaka, 2003). Overnight fasting eliminated $\mathrm{PrRP}^{+}$neural c-Fos activation under baseline conditions and after EP exposure, and substantially attenuated RES-induced activation. Thus, $\operatorname{PrRP}^{+} \mathrm{A} 2$ neurons are inhibited or otherwise silenced by overnight food deprivation, similar to GLP-1 neurons. Interestingly, similar to the effect of overnight food deprivation, intracerebroventricular injection of Ex9 attenuated the ability of RES to activate $\mathrm{PrRP}^{+} \mathrm{A} 2$ neurons in ad libitumfed rats, suggesting that GLP-1 signaling either directly or indirectly contributes to stress-induced activation of these neurons. Conversely, Ex9 pretreatment did not reduce GLP-1 neural activation after RES.

$\mathrm{PrRP}^{+} \mathrm{A} 2$ neuronal recruitment may contribute to HPA axis activation and anxiety, since these neurons project densely to the mpPVN and anterior vlBST (Maruyama et al., 1999; Morales et al., 2000; Banihashemi and Rinaman, 2006; Rinaman, 2010, 2011). Central ventricular or intra-PVN administration of norepinephrine or PrRP drives the HPA axis (Plotsky, 1987; Itoi et al., 1999; Cole and Sawchenko, 2002; Seal et al., 2002; Mera et al., 2006), and pharmacological antagonism of NA signaling or an immunotoxic lesion of A2 neurons that innervate the mpPVN and anterior vlBST attenuates anxiety and CORT responses to stress (Cecchi et al., 2002; Bienkowski and Rinaman, 2008; Zheng and Rinaman, 2013). Thus, fasting-induced suppression of $\mathrm{PrRP}^{+} \mathrm{A} 2$ neuronal signaling pathways may attenuate acute stress responses. Central PrRP receptor blockade is not currently feasible, making it difficult to test the role of endogenous PrRP signaling in behavioral and endocrine stress responses. Although central Ex9 pretreatment reduced PrRP neural activation after RES stress, our pilot study indicated that intracerebroventricular infusion alone activated robust c-Fos expression within the mpPVN that exceeded RES-induced activation, precluding the analysis of potential Ex9-mediated reductions in mpPVN activation. A previous report indicates that intracerebroventricular injection of Ex9 blunts RES-induced HPA axis responses (Kinzig et al., 2003), suggesting that the currently observed robust c-Fos response to intracerebroventricular infusion alone reflects transient and/or non-CRH neural activation.

Fasting decreases neural activation in the anterior vlBST

Neuroendocrine and anxiety-like responses to acute stress are mimicked and facilitated by central GLP-1, PrRP, and NA signaling within the mpPVN and anterior vlBST (Cecchi et al., 2002; Kinzig et al., 2003; Rinaman, 2010, 2011; Maniscalco et al., 2013). 
The anterior vlBST exerts control over autonomic, neuroendocrine, and behavioral responses to homeostatic threats via efferent projections to the mpPVN, central nucleus of the amygdala, periaqueductal gray, and other brain regions (Gray and Magnuson, 1992; Dong et al., 2001; Crestani et al., 2013). The anterior vlBST receives moderate innervation by GLP-1 neurons (Rinaman, 2011) and particularly dense innervation from $\operatorname{PrRP}^{+} \mathrm{A} 2$ neurons (Figs. 6, 8). Considering this, we hypothesized that fasting-induced silencing of GLP-1 and PrRP ${ }^{+}$A2 neurons would attenuate stress-induced activation of both mpPVN and anterior vlBST neurons. Although a main effect of feeding status on mpPVN c-Fos activation failed to reach statistical significance $(p=0.07)$, stress-induced activation of neurons within the anterior vlBST was significantly attenuated in fasted rats, perhaps contributing to the anxiolytic effect of overnight food deprivation observed in rats tested in the EPMZ. Indeed, the present study demonstrated that pretreatment with intracerebroventricular injection of Ex9 significantly attenuated RES-induced c-Fos within the PrRP-rich region of the anterior vlBST, which is consistent with results of a previous study reporting that intracerebroventricular injection of $\mathrm{Ex} 9$ reduces anxiety-like behavior in the EPMZ (Kinzig et al., 2003).

\section{Mechanisms underlying fasting-induced suppression of GLP- 1 and PrRP/A2 neural activation}

Since rats consume most of their calories during the dark period, a single overnight fast generates acute negative energy balance and elicits marked changes in physiology, including overnight activation of the HPA axis (Akana et al., 1994; Dallman et al., 1999), loss of body weight, and a $30 \%$ drop in plasma glucose levels (present results). Presumably, overnight fasting generates feedback signals that inhibit GLP-1 and PrRP/A2 neurons, desensitize them to excitatory inputs, and/or silence those inputs during the subsequent light cycle (i.e., when experiments were conducted in the present study). GLP-1 and noradrenergic PrRP neurons comprise only a small subset of all cNTS neurons that are sensitive to visceral sensory feedback, but they collectively provide most neural output from the cNTS to the hypothalamus and limbic forebrain, and are implicated in mediating endocrine and behavioral stress responses (Rinaman, 2010; Maniscalco et al., 2013). We did not quantify the effects of overnight fasting on total cNTS neural activation after acute stress, and do not argue that the effects of fasting are specific only to GLP-1 and PrRP neurons. Neurons within the cNTS receive direct glutamatergic innervation from vagal afferent neurons as well as central inputs from a variety of brainstem, hypothalamic, and limbic forebrain regions, and cNTS neurons also are sensitive to circulating factors (e.g., leptin and ghrelin) that convey information regarding digestive and metabolic status (Altschuler et al., 1989; Miselis et al., 1991; Schwartz et al., 1991; Stornetta et al., 2002; Appleyard et al., 2007; Hisadome et al., 2010; Potes and Lutz, 2010; Maniscalco et al., 2013). Fasting presumably reduces some excitatory inputs and/or increases some inhibitory inputs to the cNTS, including inputs to GLP-1 and A2 neurons, thereby preventing their activation after acute visceral (Maniscalco and Rinaman, 2013) or nonvisceral stress (present study). Additional research is warranted to identify the nature and source of these inputs.

\section{Conclusions}

Results from the present study indicate that a single overnight fast decreases anxiety-like behavior, markedly reduces the ability of acute stress to activate GLP- 1 and $\mathrm{PrRP}^{+} \mathrm{A} 2$ neurons within the cNTS, and attenuates stress-induced neuronal activation within the NA/PrRP terminal-rich vlBST. Our results also establish a role for endogenous GLP-1 receptor signaling in central neural activation and behavioral responses to acute stress. We conclude that metabolic tuning of hindbrain GLP-1 neurons (and perhaps $\mathrm{PrRP}^{+} \mathrm{A} 2$ neurons) is a potential mechanism through which negative energy balance decreases central drive to the HPA axis, promotes anxiolysis, and attenuates hypophagic responses to acute stress.

\section{References}

Acuna-Goycolea C, van den Pol A (2004) Glucagon-like peptide 1 excites hypocretin/orexin neurons by direct and indirect mechanisms: implications for viscera-mediated arousal. J Neurosci 24:8141-8152. CrossRef Medline

Akana SF, Strack AM, Hanson ES, Dallman MF (1994) Regulation of activity in the hypothalamo-pituitary-adrenal axis is integral to a larger hypothalamic system that determines caloric flow. Endocrinology 135:1125-1134. CrossRef Medline

Altschuler SM, Bao XM, Bieger D, Hopkins DA, Miselis RR (1989) Viscerotopic representation of the upper alimentary tract in the rat: sensory ganglia and nuclei of the solitary and spinal trigeminal tracts. J Comp Neurol 283:248-268. CrossRef Medline

Appleyard SM, Marks D, Kobayashi K, Okano H, Low MJ, Andresen MC (2007) Visceral afferents directly activate catecholamine neurons in the solitary tract nucleus. J Neurosci 27:13292-13302. CrossRef Medline

Banihashemi L, Rinaman L (2006) Noradrenergic inputs to the bed nucleus of the stria teminalis and paraventricular nucleus of the hypothalamus underlie hypothalamic-pituitary-adrenal axis but not hypophagic or conditioned avoidance responses to systemic yohimbine. J Neurosci 26: 11442-11453. CrossRef Medline

Bienkowski MS, Rinaman L (2008) Noradrenergic inputs to the paraventricular hypothalamus contribute to hypothalamic-pituitary-adrenal axis and central Fos activation in rats after acute systemic endotoxin exposure. Neuroscience 156:1093-1102. CrossRef Medline

Brady LS, Smith MA, Gold PW, Herkenham M (1990) Altered expression of hypothalamic neuropeptide mRNAs in food-restricted and fooddeprived rats. Neuroendocrinology 52:441-447. CrossRef Medline

Calvez J, Fromentin G, Nadkarni N, Darcel N, Even P, Tomé D, Ballet N, Chaumontet $C$ (2011) Inhibition of food intake induced by acute stress in rats is due to satiation effects. Physiol Behav 104:675-683. CrossRef Medline

Cecchi M, Khoshbouei H, Javors M, Morilak DA (2002) Modulatory effects of norepinephrine in the lateral bed nucleus of the stria terminalis on behavioral and neuroendocrine responses to acute stress. Neuroscience 112:13-21. CrossRef Medline

Chacón F, Esquifino AI, Perelló M, Cardinali DP, Spinedi E, Alvarez MP (2005) 24-hour changes in ACTH, corticosterone, growth hormone, and leptin levels in young male rats subjected to calorie restriction. Chronobiol Int 22:253-265. CrossRef Medline

Charmandari E, Tsigos C, Chrousos G (2005) Endocrinology of the stress response. Annu Rev Physiol 67:259-284. CrossRef Medline

Cole RL, Sawchenko PE (2002) Neurotransmitter regulation of cellular activation and neuropeptide gene expression in the paraventricular nucleus of the hypothalamus. J Neurosci 22:959-969. Medline

Crestani CC, Alves FH, Gomes FV, Resstel LB, Correa FM, Herman JP (2013) Mechanisms in the bed nucleus of the stria terminalis involved in control of autonomic and neuroendocrine functions: a review. Curr Neuropharmacol 11:141-159. CrossRef Medline

Dallman MF, Akana SF, Bhatnagar S, Bell ME, Choi S, Chu A, Horsley C, Levin N, Meijer O, Soriano LR, Strack AM, Viau V (1999) Starvation: early signals, sensors, and sequelae. Endocrinology 140:4015-4023. CrossRef Medline

Davis M (2002) Neural circuitry of anxiety and stress disorders. In: Neuropsychopharmacology: the 5th generation of progress (Davis KL, Charney D, Coyle JT, Nemeroff C, eds), pp 931-951. Philadelphia, PA: Lippincott, Williams \& Wilkins.

Davis M, Walker DL, Lee Y (1997a) Roles of the amygdala and bed nucleus of the stria terminalis in fear and anxiety measured with the acoustic startle reflex. Possible relevance to PTSD. Ann N Y Acad Sci 821:305-331. CrossRef Medline

Davis M, Walker DL, Lee Y (1997b) Amygdala and bed nucleus of the stria 
terminalis: differential roles in fear and anxiety measured with the acoustic startle reflex. Philos Trans R Soc Lond B Biol Sci 352:1675-1687. CrossRef Medline

Davis M, Walker DL, Miles L, Grillon C (2010) Phasic vs sustained fear in rats and humans: role of the extended amygdala in fear vs anxiety. Neuropsychopharmacology 35:105-135. CrossRef Medline

Dayas CV, Day TA (2002) Opposing roles for medial and central amygdala in the initiation of noradrenergic cell responses to a psychological stressor. Eur J Neurosci 15:1712-1718. CrossRef Medline

Dayas CV, Buller KM, Day TA (2004) Hypothalamic paraventricular nucleus neurons regulate medullary catecholamine cell responses to restraint stress. J Comp Neurol 478:22-34. CrossRef Medline

Dong HW, Petrovich GD, Watts AG, Swanson LW (2001) Basic organization of projections from the oval and fusiform nuclei of the bed nuclei of the stria terminalis in adult rat brain. J Comp Neurol 436:430-455. CrossRef Medline

Genn RF, Tucci SA, Thomas A, Edwards JE, File SE (2003) Age-associated sex differences in response to food deprivation in two animal tests of anxiety. Neurosci Biobehav Rev 27:155-161. CrossRef Medline

Gray TS, Magnuson DJ (1992) Peptide immunoreactive neurons in the amygdala and the bed nucleus of the stria terminalis project to the midbrain central gray in the rat. Peptides 13:451-460. CrossRef Medline

Grill HJ, Carmody JS, Amanda Sadacca L, Williams DL, Kaplan JM (2004) Attenuation of lipopolysaccharide anorexia by antagonism of caudal brainstem but not forebrain GLP-1 receptors. Am J Physiol Regul Integr Comp Physiol 287:R1190-R1193. CrossRef Medline

Groenink L, Bijlsma EY, Olivier B (2008) Fear-potentiated startle and lightenhanced startle models in drug discovery. Curr Protoc Pharmacol Chapter 5:Unit5.48. CrossRef Medline

Gülpinar MA, Bozkurt A, Coşkun T, Ulusoy NB, Yegen BC (2000) Glucagon-like peptide (GLP-1) is involved in the central modulation of fecal output in rats. Am J Physiol Gastrointest Liver Physiol 278:G924G929. Medline

Hanson ES, Bradbury MJ, Akana SF, Scribner KS, Strack AM, Dallman MF (1994) The diurnal rhythm in adrenocorticotropin responses to restraint in adrenalectomized rats is determined by caloric intake. Endocrinology 134:2214-2220. CrossRef Medline

Heiderstadt KM, McLaughlin RM, Wright DC, Walker SE, Gomez-Sanchez CE (2000) The effect of chronic food and water restriction on open-field behaviour and serum corticosterone levels in rats. Lab Anim 34:20-28. CrossRef Medline

Hisadome K, Reimann F, Gribble FM, Trapp S (2010) Leptin directly depolarizes preproglucagon neurons in the nucleus tractus solitarius: electrical properties of glucagon-like peptide 1 neurons. Diabetes 59:1890-1898. CrossRef Medline

Inoue K, Zorrilla EP, Tabarin A, Valdez GR, Iwasaki S, Kiriike N, Koob GF (2004) Reduction of anxiety after restricted feeding in the rat: implication for eating disorders. Biol Psychiatry 55:1075-1081. CrossRef Medline

Itoi K, Helmreich DL, Lopez-Figueroa MO, Watson SJ (1999) Differential regulation of corticotropin-releasing hormone and vasopressin gene transcription in the hypothalamus by norepinephrine. J Neurosci 19: 5464-5472. Medline

Kinzig KP, D’Alessio DA, Herman JP, Sakai RR, Vahl TP, Figueiredo HF, Murphy EK, Seeley RJ, Figueredo HF (2003) CNS glucagon-like peptide-1 receptors mediate endocrine and anxiety responses to interoceptive and psychogenic stressors. J Neurosci 23:6163-6170. Medline

Kiss A, Jezova D, Aguilera G (1994) Activity of the hypothalamic pituitary adrenal axis and sympathoadrenal system during food and water deprivation in the rat. Brain Res 663:84-92. CrossRef Medline

Krahn DD, Gosnell BA, Grace M, Levine AS (1986) CRF antagonist partially reverses CRF- and stress-induced effects on feeding. Brain Res Bull 17: 285-289. CrossRef Medline

Krahn DD, Gosnell BA, Levine AS, Morley JE (1988) Behavioral effects of corticotropin-releasing factor: localization and characterization of central effects. Brain Res 443:63-69. CrossRef Medline

Larsen PJ, Tang-Christensen M, Holst JJ, Orskov C (1997) Distribution of glucagon-like peptide-1 and other preproglucagon-derived peptides in rat hypothalamus and brainstem. Neuroscience 77:257-270. CrossRef Medline

Lennie TA, McCarthy DO, Keesey RE (1995) Body energy status and the metabolic response to acute inflammation. Am J Physiol 269:R1024R1031. Medline
Levay EA, Govic A, Penman J, Paolini AG, Kent S (2007) Effects of adultonset calorie restriction on anxiety-like behavior in rats. Physiol Behav 92:889-896. CrossRef Medline

Maniam J, Morris MJ (2012) The link between stress and feeding behaviour. Neuropharmacology 63:97-110. CrossRef Medline

Maniscalco JW, Rinaman L (2013) Overnight food deprivation markedly attenuates hindbrain noradrenergic, glucagon-like peptide-1, and hypothalamic neural responses to exogenous cholecystokinin in male rats. Physiol Behav 121:35-42. CrossRef Medline

Maniscalco JW, Kreisler AD, Rinaman L (2013) Satiation and stressinduced hypophagia: examining the role of hindbrain neurons expressing prolactin-releasing peptide or glucagon-like peptide 1. Front Neurosci 6:199. CrossRef Medline

Martin-Iverson MT, Stevenson KN (2005) Apomorphine effects on emotional modulation of the startle reflex in rats. Psychopharmacology (Berl) 181:60-70. CrossRef Medline

Maruyama M, Matsumoto H, Fujiwara K, Kitada C, Hinuma S, Onda H, Fujino M, Inoue K (1999) Immunocytochemical localization of prolactin-releasing peptide in the rat brain. Endocrinology 140:23262333. CrossRef Medline

Maruyama M, Matsumoto H, Fujiwara K, Noguchi J, Kitada C, Fujino M, Inoue K (2001) Prolactin-releasing peptide as a novel stress mediator in the central nervous system. Endocrinology 142:2032-2038. CrossRef Medline

Mera T, Fujihara H, Kawasaki M, Hashimoto H, Saito T, Shibata M, Saito J, Oka T, Tsuji S, Onaka T, Ueta Y (2006) Prolactin-releasing peptide is a potent mediator of stress responses in the brain through the hypothalamic paraventricular nucleus. Neuroscience 141:1069-1086. CrossRef Medline

Miselis RR, Rinaman L, Altschuler SM, Bao X, Lynn RB (1991) Medullary viscerotopic representation of the alimentary canal innervation in rat. In: Brain-gut interactions (Tache Y, Wingate D, eds), pp 3-17. Boca Raton, FL: CRC.

Montgomery KC (1958) The relation between fear induced by novel stimulation and exploratory behavior. J Comp Physiol Psychol 48:254-260. Medline

Morales T, Sawchenko PE (2003) Brainstem prolactin-releasing peptide neurons are sensitive to stress and lactation. Neuroscience 121:771-778. CrossRef Medline

Morales T, Hinuma S, Sawchenko PE (2000) Prolactin-releasing peptide is expressed in afferents to the endocrine hypothalamus, but not in neurosecretory neurones. J Neuroendocrinol 12:131-140. Medline

O'Shea D, Gunn I, Chen X, Bloom S, Herbert J (1996) A role for central glucagon-like peptide-1 in temperature regulation. Neuroreport 7:830832. CrossRef Medline

Pellow S, Chopin P, File SE, Briley M (1985) Validation of open: closed arm entries in an elevated plus-maze as a measure of anxiety in the rat. J Neurosci Methods 14:149-167. CrossRef Medline

Plotsky PM (1987) Facilitation of immunoreactive corticotropin-releasing factor secretion into the hypophysial-portal circulation after activation of catecholaminergic pathways or central norepinephrine injection. Endocrinology 121:924-930. CrossRef Medline

Potes CS, Lutz TA (2010) Brainstem mechanisms of amylin-induced anorexia. Physiol Behav 100:511-518. CrossRef Medline

Rinaman L (1999a) Interoceptive stress activates glucagon-like peptide-1 neurons that project to the hypothalamus. Am J Physiol 277:R582-R590. Medline

Rinaman L (1999b) A functional role for central glucagon-like peptide-1 receptors in lithium chloride-induced anorexia. Am J Physiol 277:R1537R1540. Medline

Rinaman L (2003) Hindbrain noradrenergic lesions attenuate anorexia and alter central cFos expression in rats after gastric viscerosensory stimulation. J Neurosci 23:10084-10092. Medline

Rinaman L (2007) Visceral sensory inputs to the endocrine hypothalamus. Front Neuroendocrinol 28:50-60. CrossRef Medline

Rinaman L (2010) Ascending projections from the caudal visceral nucleus of the solitary tract to brain regions involved in food intake and energy expenditure. Brain Res 1350:18-34. CrossRef Medline

Rinaman L (2011) Hindbrain noradrenergic A2 neurons: diverse roles in autonomic, endocrine, cognitive, and behavioral functions. Am J Physiol Regul Integr Comp Physiol 300:R222-R235. CrossRef Medline

Rinaman L, Dzmura V (2007) Experimental dissociation of neural circuits 
underlying conditioned avoidance and hypophagic responses to lithium chloride. Am J Physiol Regul Integr Comp Physiol 293:R1495-R1503. CrossRef Medline

Ritter S, Watts AG, Dinh TT, Sanchez-Watts G, Pedrow C (2003) Immunotoxin lesion of hypothalamically projecting norepinephrine and epinephrine neurons differentially affects circadian and stressor-stimulated corticosterone secretion. Endocrinology 144:1357-1367. CrossRef Medline

Rothwell NJ (1990) Central effects of CRF on metabolism and energy balance. Neurosci Biobehav Rev 14:263-271. CrossRef Medline

Rybkin II, Zhou Y, Volaufova J, Smagin GN, Ryan DH, Harris RB (1997) Effect of restraint stress on food intake and body weight is determined by time of day. Am J Physiol 273:R1612-R1622. Medline

Sarkar S, Fekete C, Légrádi G, Lechan RM (2003) Glucagon like peptide-1 (7-36) amide (GLP-1) nerve terminals densely innervate corticotropinreleasing hormone neurons in the hypothalamic paraventricular nucleus. Brain Res 985:163-168. CrossRef Medline

Schiltz JC, Sawchenko PE (2007) Specificity and generality of the involvement of catecholaminergic afferents in hypothalamic responses to immune insults. J Comp Neurol 502:455-467. CrossRef Medline

Schwartz GJ, McHugh PR, Moran TH (1991) Integration of vagal afferent responses to gastric loads and cholecystokinin in rats. Am J Physiol 261: R64-R69. Medline

Seal LJ, Small CJ, Dhillo WS, Kennedy AR, Ghatei MA, Bloom SR (2002) Prolactin-releasing peptide releases corticotropin-releasing hormone and increases plasma adrenocorticotropin via the paraventricular nucleus of the hypothalamus. Neuroendocrinology 76:70-78. CrossRef Medline

Stornetta RL, Sevigny CP, Guyenet PG (2002) Vesicular glutamate transporter DNPI/VGLUT2 mRNA is present in C1 and several other groups of brainstem catecholaminergic neurons. J Comp Neurol 444:191-206. CrossRef Medline
Turton MD, O'Shea D, Gunn I, Beak SA, Edwards CM, Meeran K, Choi SJ, Taylor GM, Heath MM, Lambert PD, Wilding JP, Smith DM, Ghatei MA, Herbert J, Bloom SR (1996) A role for glucagon-like peptide-1 in the central regulation of feeding. Nature 379:69-72. CrossRef Medline

Walf AA, Frye CA (2007) The use of the elevated plus maze as an assay of anxiety-related behavior in rodents. Nat Protoc 2:322-328. CrossRef Medline

Walker DL, Davis M (1997) Anxiogenic effects of high illumination levels assessed with the acoustic startle response in rats. Biol Psychiatry 42:461471. CrossRef Medline

Watson RE Jr, Wiegand ST, Clough RW, Hoffman GE (1986) Use of cryoprotectant to maintain long-term peptide immunoreactivity and tissue morphology. Peptides 7:155-159. CrossRef Medline

Yamamoto H, Lee CE, Marcus JN, Williams TD, Overton JM, Lopez ME, Hollenberg AN, Baggio L, Saper CB, Drucker DJ, Elmquist JK (2002) Glucagon-like peptide-1 receptor stimulation increases blood pressure and heart rate and activates autonomic regulatory neurons. J Clin Invest 110:43-52. CrossRef Medline

Youngblood BD, Ryan DH, Harris RB (1997) Appetitive operant behavior and free-feeding in rats exposed to acute stress. Physiol Behav 62:827830. CrossRef Medline

Zheng H, Rinaman L (2013) Yohimbine anxiogenesis in the elevated plus maze requires hindbrain noradrenergic neurons that target the anterior ventrolateral bed nucleus of the stria terminalis. Eur J Neurosci 37:1340 1349. CrossRef Medline

Zheng H, Cai L, Rinaman L (2015) Distribution of glucagon-like peptide 1-immunopositive neurons in human caudal medulla. Brain Struct Funct 220:1213-1219. CrossRef Medline

Zhu LL, Onaka T (2003) Facilitative role of prolactin-releasing peptide neurons in oxytocin cell activation after conditioned-fear stimuli. Neuroscience 118:1045-1053. CrossRef Medline 